\title{
Structure of strontium tellurite glass, anti-glass and crystalline phases by high-energy X-ray diffraction, reverse Monte Carlo and Rietveld analysis
}

\section{Rajinder Kaur, Atul Khanna, Hirdesh, Ann-Christin Dippel, Olof Gutowski, Fernando González and Marina González-Barriuso}

Acta Cryst. (2020). B76, 108-121

\section{IUCr Journals CRYSTALLOGRAPHY JOURNALS ONLINE \\ Copyright (C) International Union of Crystallography \\ Author(s) of this article may load this reprint on their own web site or institutional repository provided that this cover page is retained. Republication of this article or its storage in electronic databases other than as specified above is not permitted without prior permission in writing from the IUCr. \\ For further information see http://journals.iucr.org/services/authorrights.html}




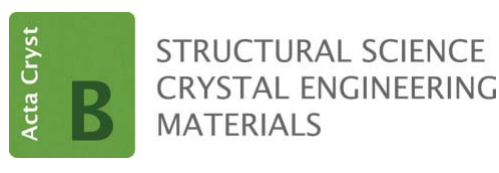

ISSN 2052-5206

Received 2 December 2019

Accepted 3 January 2020

Edited by T. R. Welberry, Australian National University, Australia

Keywords: tellurite glasses and anti-glasses; high-energy X-ray diffraction; reverse Monte Carlo simulations; Rietveld refinement.

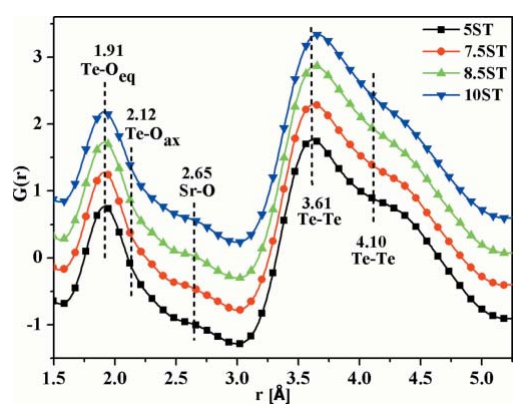

(C) 2020 International Union of Crystallography

\section{Structure of strontium tellurite glass, anti-glass and crystalline phases by high-energy X-ray diffraction, reverse Monte Carlo and Rietveld analysis}

\author{
Rajinder Kaur, ${ }^{a}$ Atul Khanna, ${ }^{\text {a* }}$ Hirdesh, ${ }^{a}$ Ann-Christin Dippel, ${ }^{b}$ Olof Gutowski, \\ Fernando González ${ }^{\mathrm{c}}$ and Marina González-Barriuso ${ }^{\mathrm{c}}$
}

aDepartment of Physics, Guru Nanak Dev University, Amritsar, Punjab 143005, India, 'beutsches Elektronen-
Synchrotron DESY, Notkestrasse 85, 22607 Hamburg, Germany, and ${ }^{\mathbf{b}}$ Department of Chemistry and Process and
Resource Engineering, University of Cantabria, Santander 39005, Spain. *Correspondence e-mail: atul.phy@gndu.ac.in

The structures of $x \mathrm{SrO}-(100-x) \mathrm{TeO}_{2}(x=5,7.5,8.5$ and 10 mol.\% $)$ glass, antiglass and crystalline samples were studied by high-energy X-ray diffraction (HEXRD), reverse Monte Carlo (RMC) simulations, atomic pair distribution function analysis and Fullprof Rietveld refinement. The atomic pair distributions show the first peak at $1.90 \AA$ due to the $\mathrm{Te}-\mathrm{O}$ equatorial bonds and the $\mathrm{Te}-\mathrm{O}$ peak is asymmetrical due to the range of $\mathrm{Te}-\mathrm{O}$ bond lengths in glass, anti-glass and crystalline samples. The short-range structural properties of glasses such as $\mathrm{Te}-\mathrm{O}$ bond lengths, $\mathrm{Te}-\mathrm{O}$ speciation, $\mathrm{Te}-\mathrm{Te}$ distances and $\mathrm{O}-$ $\mathrm{Te}-\mathrm{O}$ bond angle distributions were determined by RMC simulations. The average $\mathrm{Te}-\mathrm{O}$ coordination number $\left(N_{\mathrm{Te}-\mathrm{O}}\right)$ for $5 \mathrm{SrO}-95 \mathrm{TeO}_{2}$ glass is 3.93 which decreases to 3.59 on increasing the $\mathrm{SrO}$ concentration to $10 \mathrm{~mol}$ \%. The changes in $N_{\text {Te-O }}$ revealed that the glass network predominantly contains $\mathrm{TeO}_{4}$ units with a small amount of $\mathrm{TeO}_{3}$ units and there is a structural transformation $\mathrm{TeO}_{4} \rightarrow$ $\mathrm{TeO}_{3}$ with an increase in $\mathrm{SrO}$ concentration. The $\mathrm{O}-\mathrm{Te}-\mathrm{O}$ bond angle distributions have a peak at $79^{\circ}$ and reveal that the $\mathrm{O}_{\text {equatorial }}-\mathrm{Te}-\mathrm{O}_{\text {equatorial }}$ bonds are the most abundant linkages in the tellurite network. Two glass samples containing 7.5 and $8.5 \mathrm{~mol} \%$ of $\mathrm{SrO}$ were annealed at $350^{\circ} \mathrm{C}$ for $1 \mathrm{~h}$ to produce anti-glass phases; they were further annealed at $450^{\circ} \mathrm{C}$ for $4 \mathrm{~h}$ to transform them into crystalline phases. The anti-glass samples are disordered cubic $\mathrm{SrTe}_{5} \mathrm{O}_{11}$ and the disordered monoclinic $\mathrm{SrTeO}_{3}$ phases, whereas the crystalline samples contain monoclinic $\mathrm{SrTeO}_{3}$ and the orthorhombic $\mathrm{TeO}_{2}$ phases. The unit-cell parameters of the anti-glass and crystalline structures were determined by Fullprof Rietveld refinement. Thermal studies found that the glass transition temperature increases with an increase in $\mathrm{SrO}$ mol.\% and the results on the short-range structure of glasses from Raman spectroscopy are in agreement with the RMC findings.

\section{Introduction}

Tellurite glasses are technologically important materials due to their unique physical properties such as high refractive index, excellent non-linear optical properties, low phonon energies, wide optical transmission window, semiconducting properties and low melting temperatures (Wang et al., 1994; Rivera \& Manzani, 2017; Zhou et al., 2011; Manning, 2011). $\mathrm{TeO}_{2}$ forms glass only at a high quenching rate of $\sim 10^{5} \mathrm{~K} \mathrm{~s}^{-1}$ by roller quenching and therefore it is considered to be a conditional glass former (Barney et al., 2013). On adding modifiers such as alkali, alkaline earth and transition metal oxides into $\mathrm{TeO}_{2}$, bulk glass samples can be prepared easily at a moderate quenching rate of $\sim 10^{2} \mathrm{~K} \mathrm{~s}^{-1}$ (El-Mallawany, 2011; Kaur, Kaur et al., 2018; Kaur, Khanna et al., 2018). 
Several tellurite systems are known to produce anti-glass materials (Burckhardt \& Trömel, 1983; Kaur, Khanna et al., 2018; Bertrand et al., 2015; Blasse et al., 1986; Trömel et al., 1985, 1988; Gupta \& Khanna, 2018; Gupta et al., 2019; Wilding et al., 2016). An anti-glass is a disordered crystalline solid in which the cations $\left(\mathrm{Te}^{4+}, \mathrm{Bi}^{3+}, \mathrm{La}^{3+}, \mathrm{Nb}^{5+}, \mathrm{Sr}^{2+}\right.$ etc. $)$ have longrange order but are statistically distributed over the sites, while the anion (oxygens) sites are partly vacant and the anions are also arranged in a disorderly way. In other words, a prominent long-range order of the cations contrasts with the highly disturbed short-range order of anions, i.e. there is order and disorder co-existing in anti-glass materials. Due to the non-periodicity of the anion sites, anti-glass is also known as an anion glass. The X-ray and neutron diffraction patterns of anti-glasses exhibit sharp peaks similar to those of crystalline materials due to the long-range order of the cations. However, all the atoms are randomly distributed from their ideal positions causing large irregularities which result in apparently high temperature factors compared with those generated by the thermal motion of atoms. This consequently produces considerable vibrational disorder and results in broad phonon bands in the infrared and Raman spectra of these samples, similar to glasses (Gupta \& Khanna, 2018; Gupta et al., 2019; Kaur, Khanna et al., 2018). The glass-forming range of the $x \mathrm{SrO}-(100-x) \mathrm{TeO}_{2}$ system is between 4.8 and $11 \mathrm{~mol} . \%$ of SrO (El-Mallawany, 2011) and slowly cooled samples are found to contain co-existing glass and anti-glass inclusion phases (Kaur, Khanna et al., 2018). The anti-glass droplets of a definite size and a particular pattern can be deliberately grown inside the glass matrix by controlled infrared laser irradiation and find application in luminescence and non-linear optical devices. It is therefore important to understand the structure of glass, anti-glass and crystalline phases of the same material/ composition.

Crystalline $\mathrm{TeO}_{2}$ exists in $\alpha, \beta$ and $\gamma$ polymorphs; $\alpha$ and $\beta$ phases are more common but the glass structure is best described by the metastable $\gamma-\mathrm{TeO}_{2}$ phase (Barney et al., 2013; Li et al., 2010). The $\alpha$ and $\beta$ phases consist of trigonal bipyramidal (tbp) units along with a lone pair of electrons at the equatorial positions and have a tellurium-oxygen coordination number $\left(N_{\mathrm{Te}-\mathrm{O}}\right)$ equal to 4 , while in the $\gamma-\mathrm{TeO}_{2}$ phase one of the $\mathrm{Te}-\mathrm{O}_{\mathrm{ax}}(\mathrm{ax}=$ axial $)$ bonds in the $\mathrm{TeO}_{4}$ units undergoes elongation. The elongated $\mathrm{TeO}_{4}$ polyhedra are usually identified as $\mathrm{TeO}_{3+1}$ and the coordination number $\left(N_{\mathrm{Te}-\mathrm{O}}\right)$ in glassy $\mathrm{TeO}_{2}$ decreases to $\sim 3.68$ (Barney et al., 2013). However, determining the $\mathrm{Te}-\mathrm{O}$ coordination in tellurite materials by radial distribution function analysis is not straightforward due to the existence of a wide range of $\mathrm{Te}-\mathrm{O}$ bond lengths in the structure and it is sometimes difficult to correctly identify the $r_{\text {cut-off }}$ value (Gulenko et al., 2014; Whittles et al., 2018). The complexity of the $\mathrm{Te}-\mathrm{O}$ coordination environments is dealt with by considering five different types of $\mathrm{Te}-\mathrm{O}$ polyhedral units that exist in the crystal structures of alkali tellurites, denoted as $Q_{n}^{m}$, where $m$ is the number of bridging oxygens and $n$ represents the coordination number of the central Te atom. The $(n-m)$ value represents the number of nonbridging oxygens (NBOs). The $Q_{4}^{4}$ and $Q_{4}^{3}$ units represent trigonal bipyramids (fourfold-coordinated $\mathrm{TeO}_{4}$ units in the $\alpha$ and $\beta$ phases) while the remaining three units $Q_{3}^{0}, Q_{3}^{1}$ and $Q_{3}^{2}$ are trigonal pyramids (threefold-coordinated $\mathrm{TeO}_{3}$ units in the $\gamma$ phase) (Whittles et al., 2018; McLaughlin et al., 2000).

In the previous study (Kaur, Khanna et al., 2018), the optical and thermal properties of $x \mathrm{SrO}-(100-x) \mathrm{TeO}_{2}$ and $x \mathrm{SrO}-y \mathrm{~B}_{2} \mathrm{O}_{3}-(100-x-y) \mathrm{TeO}_{2}$ glass and anti-glass samples containing $\mathrm{Eu}^{3+}$ were reported. The present study aims at the elucidation of the short-range structure of glass, anti-glass and crystalline samples of the $x \mathrm{SrO}-(100-x) \mathrm{TeO}_{2}$ system by high-energy X-ray diffraction (HEXRD). The diffraction data sets were modelled by reverse Monte Carlo (RMC) simulations to give partial atomic pair correlations (also known as pair distribution functions, PDFs), the metal ion-oxygen coordination numbers, bond lengths and the bond angle distributions. Similarly, the structural analysis of anti-glass and crystalline phases was carried out by Rietveld refinement of the HEXRD data. The samples were also characterized by density measurements, Raman spectroscopy and differential scanning calorimetry (DSC).

\section{Experimental}

\subsection{Sample preparation}

The glass samples of the system $x \mathrm{SrO}-(100-x) \mathrm{TeO}_{2}$ with $x=5,7.5,8.5$ and $10 \mathrm{~mol} . \%$ were prepared by the splatquenching technique. The appropriate amounts of the starting materials, i.e. $\mathrm{TeO}_{2}$ (Aldrich India, 99\%) and $\mathrm{SrCO}_{3}$ (Aldrich India, 99.9\%), were weighed and mixed together in an agate mortar and pestle for about $30 \mathrm{~min}$ to homogenize the mixture, and then transferred to a platinum crucible. The mixture was melted in the furnace at $750^{\circ} \mathrm{C}$ for $\sim 1 \mathrm{~h}$. The melt in the crucible was homogenized by the occasional swirling of the crucible inside the furnace. The glass samples were prepared by splat-quenching the melt between two heavy metal blocks. The strontium tellurite system is known to produce samples that contain co-existing glass and anti-glass phases on slow normal quenching (Kaur, Khanna et al., 2018). Therefore, to get a completely glassy phase, the samples were prepared by splat-quenching which provides higher quenching rates and suppresses the growth of anti-glass droplets. All the glasses prepared in this way were clear and transparent and did not show any anti-glass inclusions on visual examination under an optical microscope.

Anti-glass phases of two compositions, $x$ SrO- $(100-x) \mathrm{TeO}_{2}$ (with $x=7.5$ and $8.5 \mathrm{~mol} . \%$ ), were prepared by annealing the initial glass samples at $350^{\circ} \mathrm{C}$ for $1 \mathrm{~h}$. The glass samples 5ST and 10ST did not produce anti-glass phases on heat treatment at $350^{\circ} \mathrm{C}$ for $1 \mathrm{~h}$ and remained amorphous; probably they required a different temperature and time for the transformation into anti-glass. Subsequently, some part of the two anti-glass samples (7.5ST_CR1 and 8.5ST_CR1) and two glass samples (5ST and 10ST) were further annealed at $450^{\circ} \mathrm{C}$ for $4 \mathrm{~h}$ to produce crystalline samples (5ST_CR2, 7.5ST_CR2, 8.5ST_CR2 and 10ST_CR2). A total of ten samples (four glass, two anti-glass and four crystalline samples) were 
Table 1

Composition, mass density $\rho$ and atomic number density $\rho_{\mathrm{o}}$ of strontium tellurite samples.

\begin{tabular}{|c|c|c|c|c|c|c|}
\hline \multirow[b]{2}{*}{ No. } & \multirow{2}{*}{$\begin{array}{l}\text { Sample } \\
\text { code }\end{array}$} & \multirow{2}{*}{$\begin{array}{l}\text { Nature of } \\
\text { sample }\end{array}$} & \multicolumn{2}{|c|}{$\begin{array}{l}\text { Composition } \\
\text { (mol.\%) }\end{array}$} & \multirow{2}{*}{$\begin{array}{l}\text { Density } \\
\rho\left(\mathrm{g} \mathrm{cm}^{-3}\right)\end{array}$} & \multirow{2}{*}{$\begin{array}{l}\rho_{8} \\
\left(\AA^{-3}\right)\end{array}$} \\
\hline & & & $\mathrm{SrO}$ & $\mathrm{TeO}_{2}$ & & \\
\hline 1 & $5 \mathrm{ST}$ & Glass & 5 & 95 & 5.63 & 0.0636 \\
\hline 2 & 5ST_CR2 & Crystalline & 5 & 95 & 5.68 & \\
\hline 3 & $7.5 \mathrm{ST}$ & Glass & 7.5 & 92.5 & 5.60 & 0.0635 \\
\hline 4 & 7.5ST_CR1 & Anti-glass & 7.5 & 92.5 & 5.66 & \\
\hline 5 & 7.5ST_CR2 & Crystalline & 7.5 & 92.5 & 5.67 & \\
\hline 6 & $8.5 \mathrm{ST}$ & Glass & 8.5 & 91.5 & 5.57 & 0.0632 \\
\hline 7 & 8.5ST_CR1 & Anti-glass & 8.5 & 91.5 & 5.59 & \\
\hline 8 & 8.5ST_CR2 & Crystalline & 8.5 & 91.5 & 5.64 & \\
\hline 9 & $10 \mathrm{ST}$ & Glass & 10 & 90 & 5.55 & 0.0629 \\
\hline 10 & 10ST_CR2 & Crystalline & 10 & 90 & 5.62 & \\
\hline
\end{tabular}

prepared (Table 1) and characterized by HEXRD, DSC and Raman spectroscopy.

\subsection{Density}

The density of all the samples was determined by the Archimedes method using dibutyl phthalate (DBP) as the immersion fluid at laboratory temperature. The density of each sample was calculated using the following relation:

$$
\rho=\frac{W_{\mathrm{A}} \rho_{\mathrm{L}}}{W_{\mathrm{A}}-W_{\mathrm{L}}},
$$

where $\rho_{\mathrm{L}}$ is the density of the immersion liquid (DBP) at room temperature, $W_{\mathrm{A}}$ and $W_{\mathrm{L}}$ are the weights of the sample in air and in DBP, respectively. The error in the density was calculated from the precision of measurement of mass by the electronic balance and it was in the range $\pm 0.001-$ $0.005 \mathrm{~g} \mathrm{~cm}^{-3}$. The densities of the samples are given in Table 1 .

\subsection{Differential scanning calorimetry (DSC)}

The thermal properties such as glass transition temperature $\left(T_{\mathrm{g}}\right)$, crystallization temperature $\left(T_{\mathrm{c}}\right)$ and melting temperature $\left(T_{\mathrm{m}}\right)$ of the powder samples were determined by the DSC technique. The endothermic transition (change in the baseline) in the DSC thermograph is the glass transition and it gives a $T_{\mathrm{g}}$ value which is a measure of the rigidity and strength of the glass network while the crystallization temperature is indicated by the exothermic peak. DSC studies were performed on the Setaram Setsys 16 TG-DSC system at a heating rate of $10^{\circ} \mathrm{C} \mathrm{min}^{-1}$ in the temperature range of 200 $800^{\circ} \mathrm{C}$ under airflow conditions. Sample amounts of $20-40 \mathrm{mg}$ were taken in platinum pans for DSC analysis. The maximum uncertainty in the measurement of $T_{\mathrm{g}}$ (mid-point), $T_{\mathrm{c}}$ (peak point) and $T_{\mathrm{m}}$ (peak point) is $\pm 1^{\circ} \mathrm{C}$. The $T_{\mathrm{g}}, T_{\mathrm{c}}$ and $T_{\mathrm{m}}$ values for the samples are given in Table 2.

\subsection{Raman spectroscopy}

The short-range structural studies were carried out on all glass, anti-glass and crystalline samples on a Renishaw In-via Reflex micro-Raman spectrometer. The Stokes spectra were generated by a $514.5 \mathrm{~nm}$ argon-ion laser as the excitation
Table 2

Thermal properties of strontium tellurite glass, anti-glass and crystalline samples.

\begin{tabular}{|c|c|c|c|c|c|c|c|c|c|c|}
\hline \multirow[b]{2}{*}{$\begin{array}{l}\text { Sample } \\
\text { code }\end{array}$} & \multirow[b]{2}{*}{$\begin{array}{l}T_{\mathrm{g}} \\
\left({ }^{\circ} \mathrm{C}\right)\end{array}$} & \multicolumn{4}{|c|}{$T_{\mathrm{c}}\left({ }^{\circ} \mathrm{C}\right)$} & \multicolumn{3}{|c|}{$T_{\mathrm{m}}\left({ }^{\circ} \mathrm{C}\right)$} & \multirow[b]{2}{*}{$\begin{array}{l}\Delta T \\
\left({ }^{\circ} \mathrm{C}\right)\end{array}$} & \multirow[b]{2}{*}{$\begin{array}{l}E_{\mathrm{B}} \\
\left(\mathrm{kJ} \mathrm{mol}^{-1}\right)\end{array}$} \\
\hline & & $T_{\mathrm{c} 1}$ & $T_{\mathrm{c} 2}$ & $T_{\mathrm{c} 3}$ & $T_{\mathrm{c} 4}$ & $T_{\mathrm{m} 1}$ & $T_{\mathrm{m} 2}$ & $T_{\mathrm{m} 3}$ & & \\
\hline $5 \mathrm{ST}$ & 309 & 353 & 474 & 538 & & 618 & 627 & 712 & 44 & 394 \\
\hline 7.5ST & 315 & 358 & 366 & 448 & 530 & 622 & 695 & & 43 & 395 \\
\hline $8.5 \mathrm{ST}$ & 319 & 359 & 404 & 443 & 533 & 623 & 686 & & 40 & 396 \\
\hline $10 \mathrm{ST}$ & 322 & 359 & 433 & & & 623 & 677 & & 37 & 397 \\
\hline 7.5ST_CR1 & 315 & 355 & 370 & 452 & 527 & 622 & 695 & & & 395 \\
\hline 8.5ST_CR1 & 318 & 358 & 404 & 449 & 532 & 623 & 687 & & & 396 \\
\hline 5ST_CR2 & & 503 & & & & 619 & 628 & 712 & & 394 \\
\hline 7.5ST_CR2 & 335 & 525 & & & & 622 & 695 & & & 395 \\
\hline 8.5ST_CR2 & 336 & 531 & & & & 623 & 687 & & & 396 \\
\hline 10ST_CR2 & & 532 & & & & 624 & 675 & & & 397 \\
\hline
\end{tabular}

source $(25 \mathrm{~mW})$ and the Raman spectra were measured in the Raman shift range of 30 to $1200 \mathrm{~cm}^{-1}$ with a spectral resolution better than $1 \mathrm{~cm}^{-1}$. Measurements were carried out at room temperature using an edge filter for Stokes spectra with a diffraction grating containing 2400 lines $\mathrm{mm}^{-1}$ and a Peltiercooled charged-coupled device detector in an unpolarized mode using backscattering geometry.

\subsection{High-energy X-ray diffraction (HEXRD)}

The HEXRD studies on the glass, anti-glass and crystalline samples were carried out at the High Energy Materials Science (HEMS) beamline (P07, second experimental hutch EH2) of the PETRA III synchrotron of the Deutsches Elektronen-Synchrotron (DESY), Hamburg, Germany. The finely powdered samples were filled into Kapton capillary tubes of diameter $2 \mathrm{~mm}$ (wall thickness of $\sim 0.02 \mathrm{~mm}$ ) and the X-ray scattering intensity was measured at room temperature. The optics for the X-ray beam consist of a double-crystal monochromator having two bent $\mathrm{Si}$ (111) Laue crystals to tune the energy range (Schell et al., 2014). The scattered intensities were measured with a 2D PerkinElmer detector XRD1621. 2D powder diffraction data were obtained and converted into 1D diffraction patterns (intensity versus $Q$ ) by using the FIT2D software (Hammersley, http://www.esrf.eu/computing/ scientific/FIT2D/) which facilitates the detector calibration and integration of powder diffraction data from $2 \mathrm{D}$ detectors.

In a diffraction experiment on amorphous materials, high values of the momentum transfer $Q(Q=4 \pi \sin \theta / \lambda, \theta$ is the diffraction angle and $\lambda$ is the wavelength of the X-rays) are necessary to achieve a high real-space resolution of the atomic pair distributions since the Fourier transform with a low $Q_{\max }$ value yields peak broadening that prevents the resolution of two close-spaced interatomic distances (Cormier, 2018). This can be done by using high incident energy, i.e. short-wavelength, X-rays. In the present work, X-ray diffraction data were measured in the high momentum transfer $Q$ range 0.47 to $25 \AA^{-1}$ using monochromatic X-rays of wavelength $\lambda=$ $0.1263 \AA$ ̊ (energy $=98.35 \mathrm{keV})$. 
Table 3

$\mathrm{X}$-ray scattering weight factors, $w_{i j}(\%)$, for the atomic pairs in strontium tellurite glasses at $Q=7.01 \AA^{-1}$.

\begin{tabular}{lllll}
\hline & \multicolumn{4}{l}{ X-ray weight factors, $w_{i j}(\%)$} \\
\cline { 2 - 5 } Atomic pair & $5 \mathrm{ST}$ & $7.5 \mathrm{ST}$ & $8.5 \mathrm{ST}$ & $10 \mathrm{ST}$ \\
\hline $\mathrm{Sr}-\mathrm{Sr}$ & 0.10 & 0.23 & 0.30 & 0.41 \\
$\mathrm{Sr}-\mathrm{Te}$ & 5.28 & 7.83 & 8.84 & 10.32 \\
$\mathrm{Sr}-\mathrm{O}$ & 0.88 & 0.13 & 1.51 & 1.78 \\
$\mathrm{Te}-\mathrm{Te}$ & 68.73 & 66.17 & 65.15 & 63.62 \\
$\mathrm{Te}-\mathrm{O}$ & 23.06 & 22.50 & 22.28 & 21.95 \\
$\mathrm{O}-\mathrm{O}$ & 1.93 & 1.91 & 1.90 & 1.89 \\
\hline
\end{tabular}

\subsection{Pair distribution function analysis by PDFgetX2}

The intensity versus $Q$ data from the HEMS beamline were converted into a structure factor $S(Q)$ with the PDFget $X 2$ software (Qiu et al., 2004). In the PDFgetX2 software, the standard corrections due to polarization of the scattered $\mathrm{X}$-rays, inelastic Compton scattering, background subtraction, sample absorption and oblique incident angle corrections were applied. The structure-factor $S(Q)$ files generated by $P D F g e t X 2$ also contain the Faber-Ziman coefficients (X-ray scattering weight factors) as a function of $Q$ (Table 3). The Fourier sine inverse transform of $S(Q)$ yields the reduced pair distribution, $G(r)$, which gives the spatial correlations between the different pairs of atoms. In the present system $\left[x \mathrm{SrO}-(100-x) \mathrm{TeO}_{2}\right]$ six atomic pair correlations, i.e. $\mathrm{Sr}-\mathrm{Sr}$, $\mathrm{Sr}-\mathrm{Te}, \mathrm{Sr}-\mathrm{O}, \mathrm{Te}-\mathrm{Te}, \mathrm{Te}-\mathrm{O}$ and $\mathrm{O}-\mathrm{O}$, exist.

The $G(r)$ is obtained from the following well-known inverse Fourier sine transformation (Petkov, 2008; Egami \& Billinge, 2003):

$$
\begin{gathered}
G(r)=4 \Pi r \rho_{o}[g(r)-1] \\
=\frac{2}{\Pi} \int_{Q_{\min }}^{Q_{\max }} Q[S(Q)-1] M(Q) \sin Q r \mathrm{~d} Q, \\
g(r)=1+\frac{1}{2 \Pi^{2} r \rho_{o}} \int_{Q_{\min }}^{Q_{\max }} Q[S(Q)-1] M(Q) \sin Q r \mathrm{~d} Q,
\end{gathered}
$$

where $M(Q)$ is the Lorch modification function and is defined as (Soper \& Barney, 2012)

$$
\begin{gathered}
M(Q)=\frac{\sin (\Delta Q)}{\Delta Q} \quad Q<Q_{\max }, \\
M(Q)=0 \quad Q>Q_{\max }, \\
\Delta=\frac{\pi}{Q_{\max }} .
\end{gathered}
$$

$g(r)$ is the atomic pair correlation function and $g(r) \rightarrow 1$ as $r$ $\rightarrow \infty$, while the reduced pair correlation function $G(r) \rightarrow 0$ as $r \rightarrow \infty$ and $\rho_{o}$ is the bulk atomic number density.
Table 4

The cut-off distances used for each atomic pair in the final RMC run for strontium tellurite glasses.

\begin{tabular}{lllll}
\hline & \multicolumn{4}{l}{$r$ cut-off values $(\AA)$} \\
\cline { 2 - 5 } Atomic pair & $5 \mathrm{ST}$ & $7.5 \mathrm{ST}$ & $8.5 \mathrm{ST}$ & $10 \mathrm{ST}$ \\
\hline $\mathrm{Sr}-\mathrm{Sr}$ & 3.20 & 3.00 & 3.20 & 3.20 \\
$\mathrm{Sr}-\mathrm{Te}$ & 2.50 & 2.50 & 2.50 & 2.50 \\
$\mathrm{Sr}-\mathrm{O}$ & 2.30 & 2.25 & 2.20 & 2.25 \\
$\mathrm{Te}-\mathrm{Te}$ & 3.00 & 2.40 & 2.60 & 3.00 \\
$\mathrm{Te}-\mathrm{O}$ & 1.67 & 1.65 & 1.65 & 1.65 \\
$\mathrm{O}-\mathrm{O}$ & 2.40 & 2.30 & 2.30 & 2.30 \\
\hline
\end{tabular}

\subsection{Reverse Monte Carlo (RMC) simulations}

$R M C++$ is a $3 \mathrm{D}$ structural modelling program used for the disordered (amorphous) structures which involves random movements of atoms placed in a simulation box with periodic boundary conditions (Kaur et al., 2019; Khanna et al., 2018; Evrard \& Pusztai, 2005; Fabian et al., 2016; Fábián \& Araczki, 2016). The RMC technique reduces the squared difference between the experimentally measured structure factor, $S_{\text {exp }}(Q)$ and the calculated one, by repeatedly sampling the configuration space (McLaughlin \& Zwanziger, 1999).

Mathematically,

$$
\chi^{2}=\frac{1}{\sigma_{i}^{2}\left(Q_{i}\right)} \sum_{i}\left[S_{\exp }\left(Q_{i}\right)-S_{\text {model }}\left(Q_{i}\right)\right]^{2}
$$

where $\sigma$ is the standard deviation of the experimental data, $S_{\text {exp }}$ is the experimental structure factor and $S_{\text {model }}$ is the calculated structure factor. For each experimental run, a new configuration is generated by the random motion of one particle and the new $\chi_{\text {new }}^{2}$ is calculated. If $\chi_{\text {new }}^{2}<\chi_{\text {original }}^{2}$, then the new configuration is accepted. However, if $\chi_{\text {new }}^{2}>\chi_{\text {original }}^{2}$, the move is accepted with a probability that follows a normal distribution. The process is repeated until $\chi_{\text {new }}^{2}$ decreases to an equilibrium value (Moharram, 2015).

RMC simulations were performed on the X-ray structurefactor data sets of four glass samples to determine the structural parameters such as the partial atomic pair correlation functions, $\mathrm{Te}-\mathrm{O}, \mathrm{Sr}-\mathrm{O}$ and $\mathrm{O}-\mathrm{O}$ speciation, bond lengths, and $\mathrm{O}-\mathrm{Te}-\mathrm{O}, \mathrm{O}-\mathrm{Sr}-\mathrm{O}$ and $\mathrm{O}-\mathrm{O}-\mathrm{O}$ bond angle distributions. The $R M C++$ program consists of the following three steps, namely Random, Moveout and Rmcppnew.

In the Random step, $N$ virtual atoms of the correct atomic number density (Table 1 ) were put into a simulation box of length $L$, having interatomic distances up to $3^{1 / 2} L / 2$. In the present case, the box contains $N=10000$ random atoms of $\mathrm{Sr}$, Te and $\mathrm{O}$. The half box length was 27.17, 27.04, 27.08 and $27.14 \AA$ for the glass samples 5ST, 7.5ST, 8.5ST and 10ST, respectively.

In the Moveout step, the atoms were moved out by using the cut-off distances or the minimum interatomic distances in the input program. In this particular step, we can apply any constraints to better model the experimental data. Here, we used cut-off distances (Table 4) as the constraints to avoid 
Table 5

$\mathrm{Te}-\mathrm{Te}$ and $\mathrm{Te}-\mathrm{O}$ bond lengths, $\mathrm{O}-\mathrm{Te}-\mathrm{O}$ bond angle, $r$ cut-off and $N_{\mathrm{Te}-\mathrm{O}}$ values for the strontium tellurite glasses by RMC and Raman analysis.

\begin{tabular}{|c|c|c|c|c|c|c|}
\hline Sample code & $\mathrm{Te}-\mathrm{Te}(\AA)$ & $\mathrm{Te}-\mathrm{O}_{\text {eq }}(\AA)$ & $\mathrm{Te}-\mathrm{O}_{\mathrm{ax}}(\AA)$ & $\mathrm{O}-\mathrm{Te}-\mathrm{O}\left({ }^{\circ}\right)$ & $N_{\mathrm{Te}-\mathrm{O}}( \pm 0.01)(\mathrm{RMC})$ & $N_{\mathrm{Te}-\mathrm{O}}( \pm 0.01)($ Raman $)$ \\
\hline $5 \mathrm{ST}$ & 3.55 & 1.90 & 2.17 & 79 & $3.93\left(r_{\min } 1.75 \AA, r_{\max } 2.39 \AA\right)$ & 3.60 \\
\hline $7.5 \mathrm{ST}$ & 3.54 & 1.90 & 2.15 & 75 & $3.84\left(r_{\min } 1.79 \AA, r_{\max } 2.25 \AA\right)$ & 3.58 \\
\hline $8.5 \mathrm{ST}$ & 3.55 & 1.90 & 2.15 & 77 & $3.82\left(r_{\min } 1.80 \AA, r_{\max } 2.30 \AA\right)$ & 3.54 \\
\hline
\end{tabular}

unnecessary atom interactions. No constraints were applied to $\mathrm{Te}-\mathrm{O}$ speciation in the RMC input program.

In the third and final step, the Rmcppnew application, the data were refined until the difference between the calculated and the experimentally derived structure factors was reduced. Repeated RMC runs were carried out by slightly modifying the cut-off distances for the various atom pairs until an almost perfect fit to the experimental data was achieved to obtain reliable partial atomic pair correlation functions, $g_{i j}(r)$.

The cut-off distances used in the final RMC run for $\mathrm{Sr}-\mathrm{Sr}$, $\mathrm{Sr}-\mathrm{Te}, \mathrm{Sr}-\mathrm{O}, \mathrm{Te}-\mathrm{Te}, \mathrm{Te}-\mathrm{O}$ and $\mathrm{O}-\mathrm{O}$ atom pairs for the four glass samples are given in Table 4 . The $r_{\min }$ and $r_{\max }$ values were used to calculate the coordination number of $\mathrm{Te}-\mathrm{O}, \mathrm{Sr}-\mathrm{O}$ and $\mathrm{O}-\mathrm{O}$ atomic pairs.

The uncertainty in the final results is obtained by repeating the RMC simulations three times on each sample and the reported errors are the maximum uncertainties in the data. After multiple RMC runs on each sample, a good convergence and reproducibility of RMC results were obtained. The experimental and the calculated structure factors $S(Q)$ of the glass samples matched well, and the output parameters including the partial atomic pair correlation functions, $g_{i j}(r)$, were generated with good reproducibility and statistics. The $\mathrm{RMC}$ results are given in Table 5.

\subsection{Fullprof Rietveld analysis of HEXRD data of anti-glass and crystalline samples}

The Rietveld suite is a refinement tool that uses a non-linear least-square method to minimize the differences between the observed peak intensities of the sample and the peaks calculated from a crystal model (Young, 1993; Toby, 2006). More precisely, the Rietveld is a multi-parameter curve-fitting procedure that fits the sample data to the structure model. The HEXRD data of the anti-glass and crystalline samples show sharp peaks. The data obtained from HEXRD are a set of intensity values measured at a set of specific momentum transfer $Q$ values and expressed as 'intensity versus $2 \theta^{\prime}$ to perform Rietveld analysis by using the $Q=4 \pi \sin \theta / \lambda$ equation.

The HEXRD peaks of the anti-glass sample correspond to two phases, face-centred $\mathrm{SrTe}_{5} \mathrm{O}_{11}$ and monoclinic $\mathrm{SrTeO}_{3}$ phases, while the peaks of the crystalline samples match well with the monoclinic $\mathrm{SrTeO}_{3}$ and the orthorhombic $\mathrm{TeO}_{2}$ phases. In the case of one anti-glass (7.5ST_CR1) and one crystalline sample (10ST_CR2), the profile matching using the constant scale factor was carried out by the Fullprof program with the pseudo-Voigt function to model the peak profile shape.

\section{Results and discussion}

\subsection{Density}

The density, $\rho$, of all the glass samples is given in Table 1. The density of the glasses decreases from 5.63 to $5.55 \mathrm{~g} \mathrm{~cm}^{-3}$ on increasing $\mathrm{SrO}$ content from 5 to $10 \mathrm{~mol} \%$. This is due to the fact that the heavier $\mathrm{TeO}_{2}$ molecules (molecular weight $=$ $159.6 \mathrm{u}$ ) are replaced by significantly lighter $\mathrm{SrO}$ molecules (molecular weight $=103.6 \mathrm{u})$. A similar argument holds for the anti-glass and crystalline samples: the density decreases with an increase in $\mathrm{SrO}$ concentration. However, the trend of density differences among the three phases is $\rho_{\text {glass }}<\rho_{\text {anti-glass }}$ $<\rho_{\text {crystalline. This is due to the fact that the amorphous samples }}$ are disordered and cannot be packed in an optimal way while in the anti-glass materials there is long-range order of cations and they therefore exhibit higher packing density than the glasses. On the other hand, crystalline samples are the most ordered system (prominent long-range order of both the cations and anions), i.e. these are 'close-packed' and hence denser than both the glass and anti-glass samples.

\subsection{Thermal properties}

DSC scans of all the glass samples are displayed in Fig. 1. The glass transition temperature $\left(T_{\mathrm{g}}\right)$ is an endothermic event, in which the abrupt change in heat capacity is illustrated by the shift in the baseline followed by an exothermic peak due to the crystallization $\left(T_{\mathrm{c}}\right)$ or the devitrification process (Affatigato, 2015). The $T_{\mathrm{g}}$ of the first sample (5ST glass) is $309^{\circ} \mathrm{C}$,

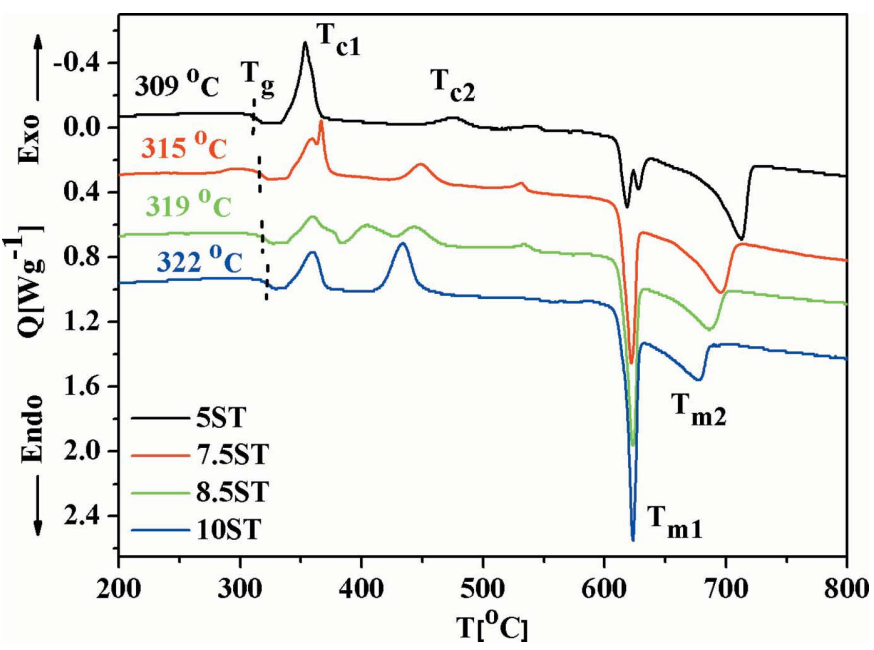

Figure 1

DSC thermographs of $x \mathrm{SrO}-(100-x) \mathrm{TeO}_{2}(x=5,7.5,8.5$ and $10 \mathrm{~mol} . \%)$ glasses. 
which increases to $322^{\circ} \mathrm{C}$ on increasing the $\mathrm{SrO}$ concentration from 5 to $10 \mathrm{~mol} \%$. This increase in $T_{\mathrm{g}}$ is due to the replacement of weaker $\mathrm{Te}-\mathrm{O}\left[E_{\mathrm{Te}-\mathrm{O}}=391(8) \mathrm{kJ} \mathrm{mol}^{-1}\right]$ linkages by significantly stronger $\mathrm{Sr}-\mathrm{O}\left[E_{\mathrm{Sr}-\mathrm{O}}=454(14) \mathrm{kJ} \mathrm{mol}^{-1}\right]$ bonds. The average single bond enthalpy, $E_{\mathrm{B}}$, for each glass sample was calculated as

$$
E_{\mathrm{B}}=\frac{x E_{\mathrm{Sr}-\mathrm{O}}+(100-x) E_{\mathrm{Te}-\mathrm{O}}}{100},
$$

with $x=5,7.5,8.5$ and $10 \mathrm{~mol} \%$. $E_{\mathrm{B}}$ increases with the increase in $\mathrm{SrO}$ concentration and therefore the $T_{\mathrm{g}}$ also increases. The $T_{\mathrm{g}}, T_{\mathrm{c}}$ and $T_{\mathrm{m}}$ values for the glasses are given in Table 2.

In the case of the anti-glass samples (xST_CR1; $x=7.5$, $8.5 \mathrm{~mol} . \%$ ), the slope of $T_{\mathrm{g}}$ is very weak (Fig. 2) because these samples are mostly anti-glass phases with only a small amount of the glassy phase. The crystalline samples xST_CR2 $(x=5$, $7.5,8.5$ and $10 \mathrm{~mol} . \%$ ) also exhibit weak glass transition (Fig. 3) compared with glass and anti-glass samples because

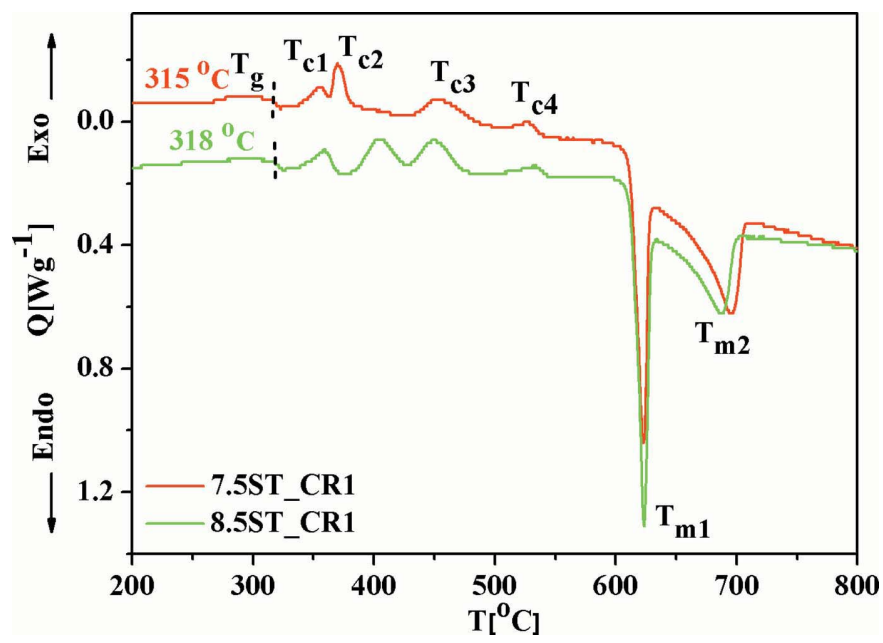

Figure 2

DSC thermographs of strontium tellurite anti-glass samples.

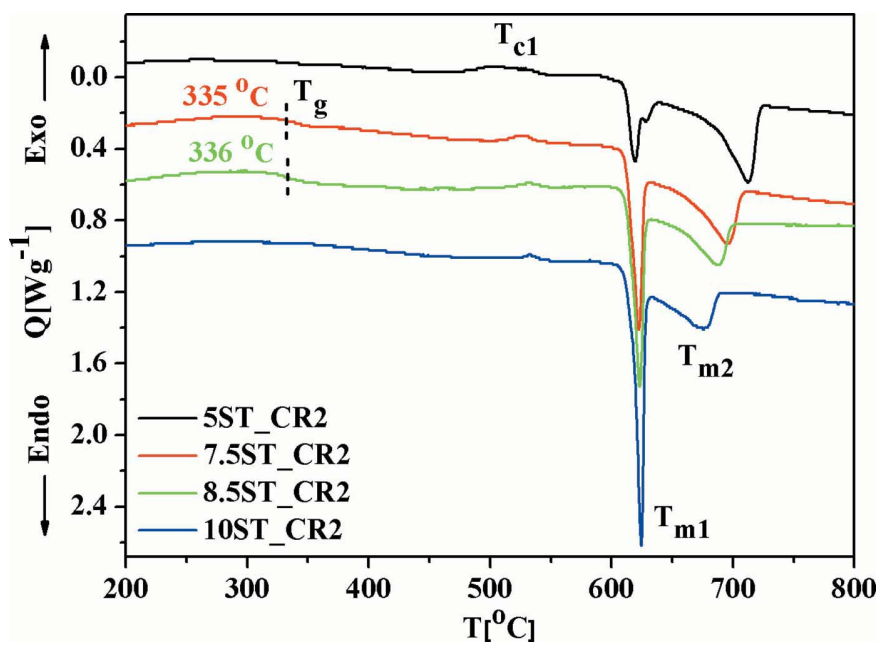

Figure 3

DSC thermographs of crystalline strontium tellurite samples. these samples are predominantly crystalline and contain very little remnant glassy phase. DSC scans of anti-glass samples (Fig. 2) exhibit exothermic crystallization peaks due to the transformation of anti-glass and remnant glassy phases into thermodynamically more stable crystalline phases on heat treatment. However, the crystallization peaks in crystalline samples (Fig. 3) are also very weak because of their crystalline nature. by

The thermal stability $\Delta T$ of the glass samples is calculated

$$
\Delta T=T_{\mathrm{c}}-T_{\mathrm{g}}
$$

The thermal stability of glasses decreases from $44^{\circ} \mathrm{C}$ to $37^{\circ} \mathrm{C}$ on increasing the SrO concentration from 5 to $10 \mathrm{~mol}$ \% which shows that the tendency towards crystallization enhances with an increase in $\mathrm{SrO}$ concentration (Table 2).

\subsection{Short-range structure by Raman spectroscopy}

The Raman spectra of the glass samples are shown in Fig. 4. It is found that the Raman spectra show broad bands in the high-frequency region and a well-resolved asymmetric sharp boson peak in the low-frequency region $\left(\sim 55 \mathrm{~cm}^{-1}\right)$. The boson peak is the characteristic feature of amorphous materials and its intensity and position depend on the composition of the glass samples. In the high-frequency region, the Raman spectra show three polarized bands: a broad band at $\sim 450 \mathrm{~cm}^{-1}$, a highly intense band at $\sim 660 \mathrm{~cm}^{-1}$ and a shoulder around $760 \mathrm{~cm}^{-1}$. These bands correspond to the bending mode of $\mathrm{Te}-\mathrm{O}-\mathrm{Te}$ and/or $\mathrm{O}-\mathrm{Te}-\mathrm{O}$ linkages, to stretching modes of the $\mathrm{TeO}_{4}$ tbp units and to the stretching modes of the $\mathrm{TeO}_{3}$ trigonal pyramidal (tp) units, respectively.

The band in the range $550-850 \mathrm{~cm}^{-1}$ for all the glass samples was baseline corrected and deconvoluted with peaks due to $\mathrm{TeO}_{4}$ and $\mathrm{TeO}_{3}$ units to calculate the Te-O coordination number. The deconvoluted spectrum of 5ST (Fig. 5)

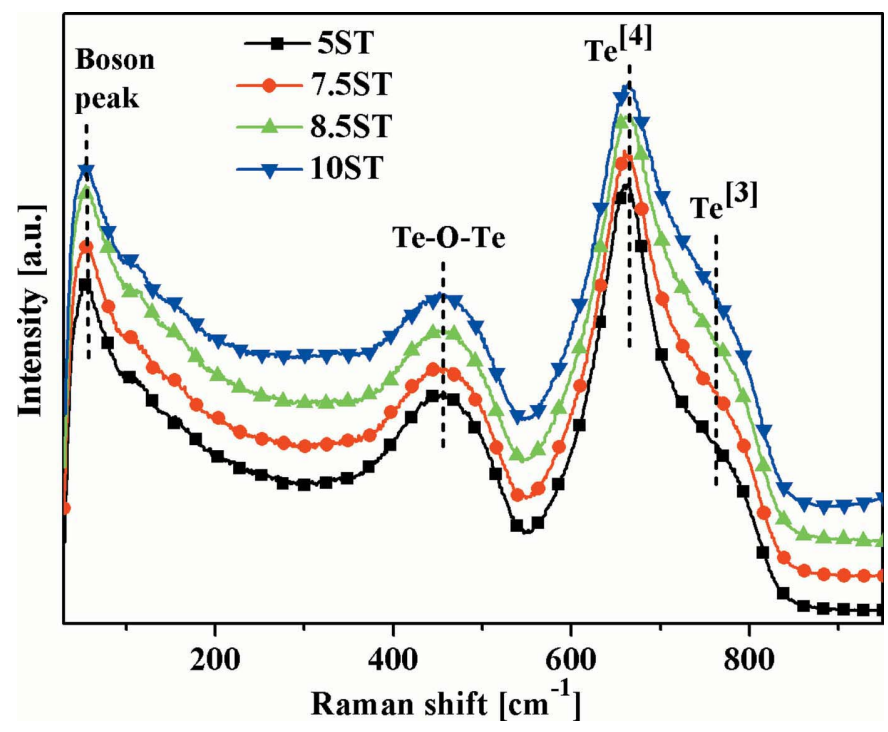

Figure 4

Raman spectra of strontium tellurite glasses. 
shows four peaks centred at $\sim 621,664,723$ and $783 \mathrm{~cm}^{-1}$. The peaks at 621 and $664 \mathrm{~cm}^{-1}$ are due to asymmetric stretching vibrations of $\mathrm{Te}-\mathrm{O}$ bonds in $\mathrm{TeO}_{4}$ units, whereas the peaks at 723 and $783 \mathrm{~cm}^{-1}$ are due to the stretching vibrations of $\mathrm{TeO}_{3}$ and $\mathrm{TeO}_{3+1}$ units (Manning, 2011). The shifting of the peak from 664 to $672 \mathrm{~cm}^{-1}$ in the strontium tellurite sample with an increase in $\mathrm{SrO}$ concentration is due to the conversion of $\mathrm{TeO}_{4}$ into $\mathrm{TeO}_{3}$ units along with the formation of NBOs. The coordination number was calculated from the deconvoluted Raman spectrum by using the formula (Kaur, Khanna et al., 2018)

$$
N_{\mathrm{Te}-\mathrm{O}}=3+\frac{A_{621}+A_{664}}{A_{621}+A_{664}+A_{723}+A_{783}},
$$

where $A$ is the area under the Gaussian peak. $N_{\mathrm{Te}-\mathrm{O}}$ decreases steadily from 3.60 (1) to 3.53 (1) (Table 5) with an increase in the concentration of $\mathrm{SrO}$ due to the conversion of $\mathrm{TeO}_{4} \rightarrow$ $\mathrm{TeO}_{3}+\mathrm{NBO}$.

The Raman spectra for the anti-glass samples are shown in Fig. 6 and we observe broad bands which are very similar to those of the glass samples. However, the band at $450 \mathrm{~cm}^{-1}$ in the glass samples shifts to $430 \mathrm{~cm}^{-1}$ in the anti-glass samples, which indicates the red shift. The latter effect is due to the improved crystallinity in the samples since the anti-glass samples possess a long-range order of cations and are more ordered than glasses. Additionally, the bond length of $\mathrm{Te}-\mathrm{O}$ linkages also increases in the case of anti-glass samples as observed from $G(r)$ distributions (discussed below). The broad Raman bands in the anti-glass samples represent the vibrational disorder due to the non-periodicity of the anionic sites in the anti-glass material. The sharp X-ray diffraction (XRD) peaks (discussed later) and the broad Raman bands confirm the anti-glass nature of xST_CR1 $(x=7.5$ and $8.5 \mathrm{~mol} \%$ ) samples.

On annealing the anti-glass samples at $450^{\circ} \mathrm{C}$ for $4 \mathrm{~h}$, crystalline phases are formed which give sharp peaks in the Raman spectra. The Raman spectra for crystalline samples

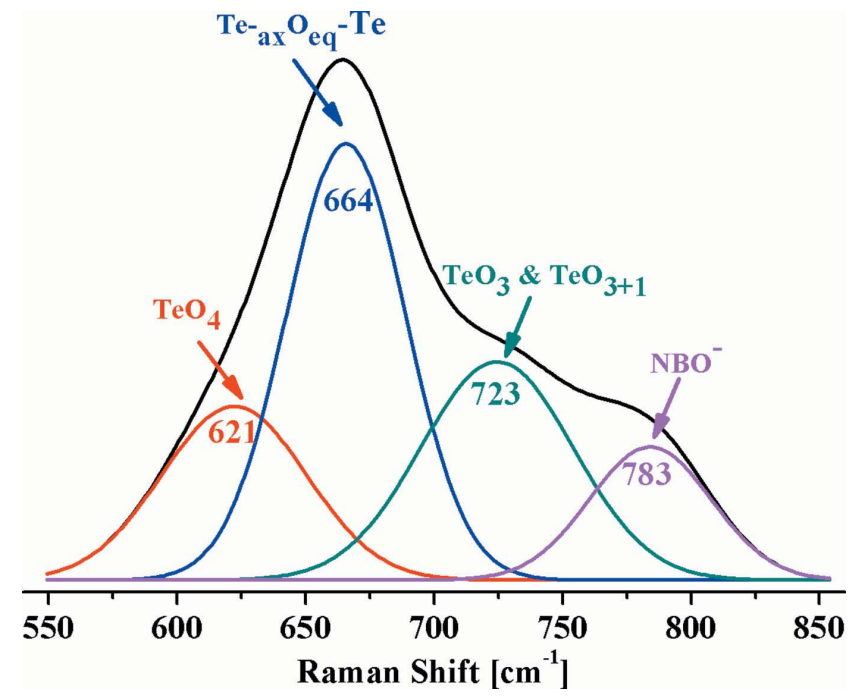

Figure 5

Deconvoluted Raman spectrum of the glass sample (5ST).
xST_CR2 $(x=5,7.5,8.5$ and 10 mol. \% $)$ are displayed in Fig. 7. The combined HEXRD and Raman studies of the samples confirm that the sample transforms as glass $\rightarrow$ anti-glass $\rightarrow$ crystalline upon heat treatment.

The short-range and long-range structural analysis of glass, anti-glass and crystalline samples was carried out using HEXRD, PDF analysis, RMC simulations and Rietveld refinement as discussed below.

\subsection{Structure of strontium tellurite glasses}

The HEXRD data of the four glass samples (xST; $x=5,7.5$, 8.5 and $10 \mathrm{~mol} \%$ ) are shown in Fig. 8. Broad peaks in the HEXRD data are due to short-range and intermediate-range order in the glasses that are evaluated by Fourier transformation and RMC analysis as discussed below.

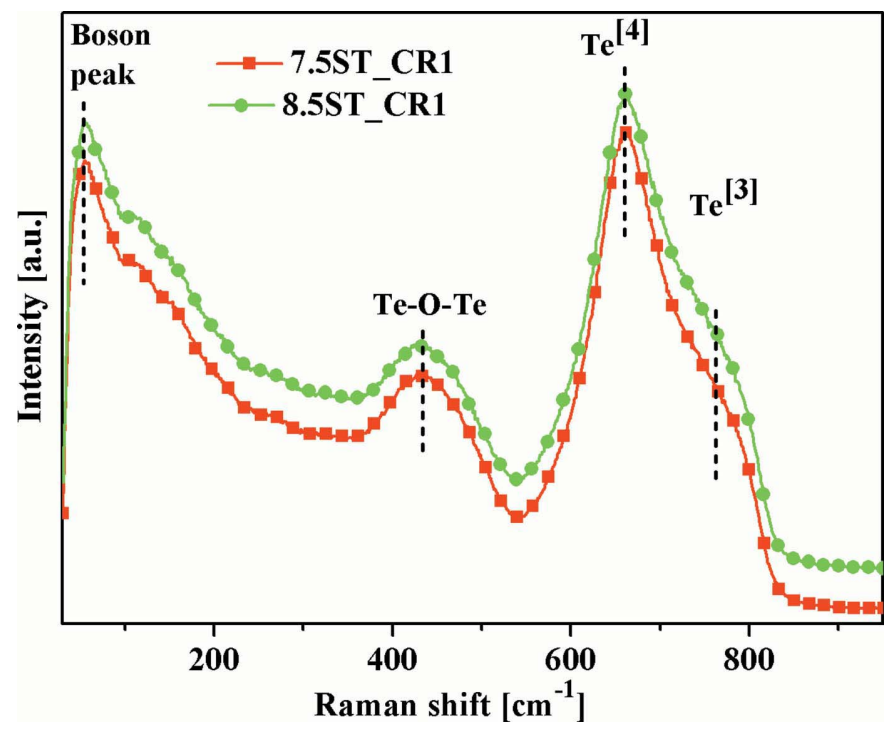

Figure 6

Raman spectra of strontium tellurite anti-glass samples.

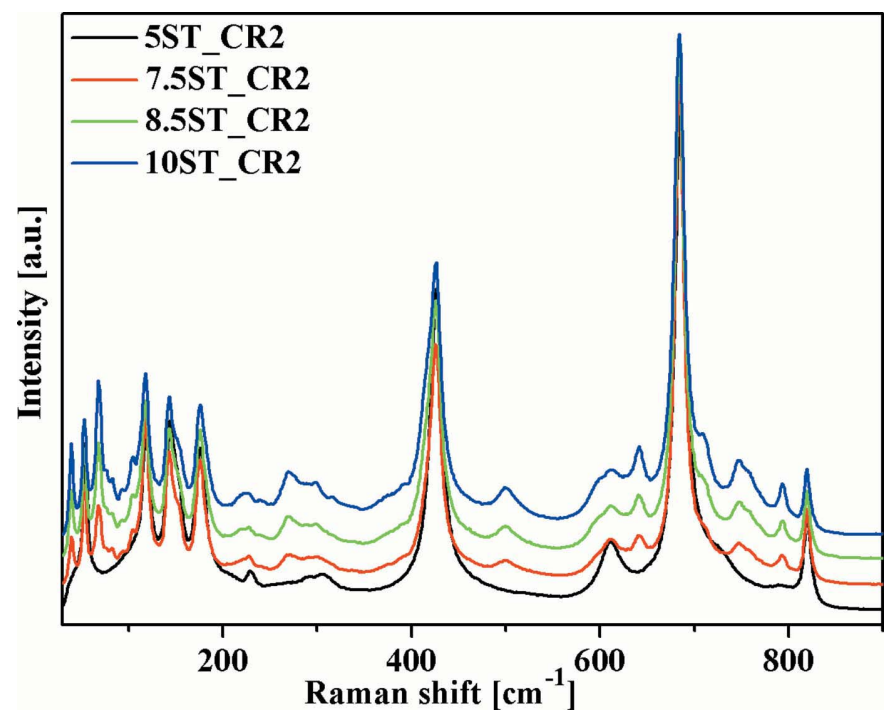

Figure 7

Raman spectra of strontium tellurite crystalline samples. 
3.4.1. The total structure factor, $S(Q)$, and first sharp diffraction peak. The X-ray structure factors $S(Q)$ (Fig. 9) were calculated with the PDFget $X 2$ software up to $Q_{\max }=$ $18.5 \AA^{-1}$. The XRD data of the glasses show an interesting feature at low $Q$ values, often referred to as the 'first sharp diffraction peak' (FSDP) (Fig. 9) (McLaughlin et al., 2001; Johnson et al., 1986; Elliott, 1991). The FSDP is due to the intermediate-range order (IRO) in covalent glasses and defines the relationship between the momentum and real spaces. It corresponds to the correlation in real space with a length scale $r=2 \pi / Q_{\mathrm{FSDP}}$ where $Q_{\mathrm{FSDP}}$ is the position of the FSDP. In general, the FSDP are in the range 0.63 to $1.9 \AA^{-1}$ due to the real-space atomic correlations between 3 and $5 \AA$ which is a typical length scale of the IRO (Moss \& Price, 1985; Salmon, 1994).

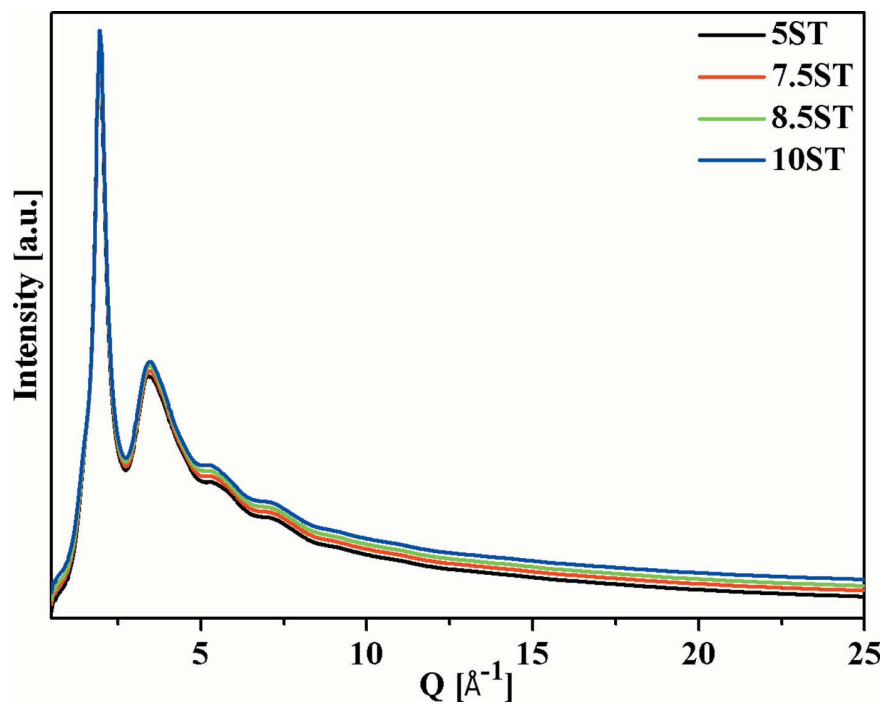

Figure 8

$\mathrm{X}$-ray scattering raw data of strontium tellurite glasses measured at the P07 beamline of the PETRA synchrotron.

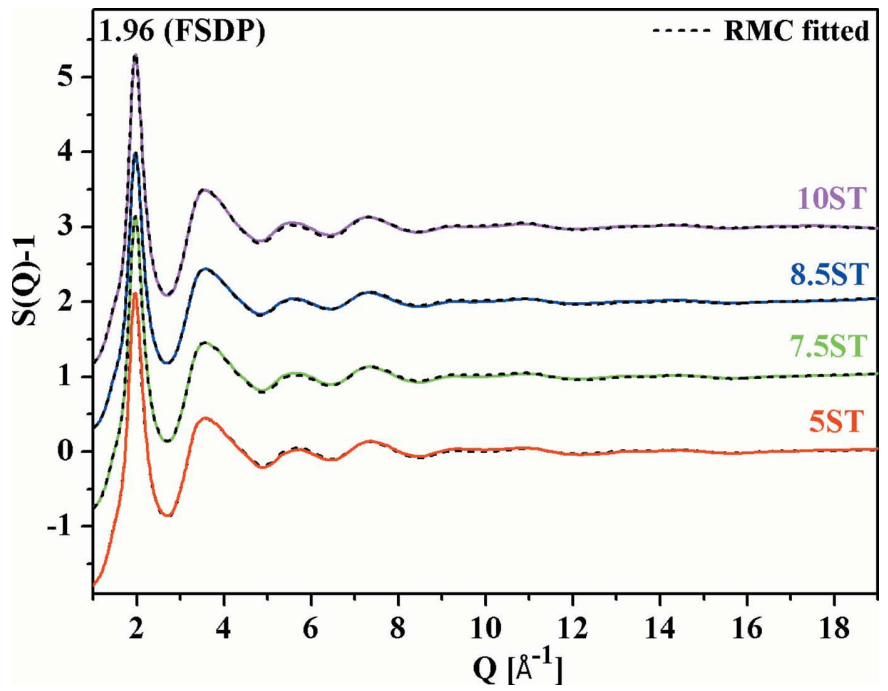

Figure 9

RMC calculated and experimental X-ray structure factors (curves are displaced successively by 1 unit for clarity).
Table 6

FSDP position and intermediate-range length scale in strontium tellurite glasses.

\begin{tabular}{lll}
\hline Sample code & $Q_{\text {FSDP }}\left(\AA^{-1}\right)$ & IRO $=2 \pi / Q_{\text {FSDP }}(\AA)$ \\
\hline 5ST & 1.95 & 3.22 \\
$7.5 \mathrm{ST}$ & 1.96 & 3.20 \\
$8.5 \mathrm{ST}$ & 1.96 & 3.20 \\
$10 \mathrm{ST}$ & 1.96 & 3.20
\end{tabular}

The glass system $x \mathrm{SrO}-(100-x) \mathrm{TeO}_{2}(x=5,7.5,8.5$ and 10 mol.\%) has a strong FSDP at $Q=1.95-1.96 \AA^{-1}$ (Fig. 9) and it corresponds to real-space distances $r=3.22-3.20 \AA$ (Table 6). These $r$ values correspond to the typical Te-Te correlations for corner-sharing units and are accountable for $\sim 50 \%$ of the intensity in the X-ray data.

3.4.2. $G(r)$ of the strontium tellurite glass samples. The reduced pair correlation function, $G(r)$ (Fig. 10), of all the glass samples was obtained from the Fourier transformation of $S(Q)$ with the Lorch modification function to reduce spurious ripples in the data. In all glasses (Fig. 10), there is a first sharp peak at $1.91 \AA$, a weak shoulder at $2.12 \AA$, a broad band at $\sim 2.65 \AA$ and another broad band in the range of 3.1-5.0. The first peak at $1.91 \AA$ is due to the shorter $\mathrm{Te}-\mathrm{O}$ equatorial bonds in the $\mathrm{TeO}_{4}$ units and represents a well-defined nearestneighbour shell (McLaughlin et al., 2000). The shoulder at $2.12 \AA$ corresponds to longer $\mathrm{Te}-\mathrm{O}_{\mathrm{ax}}$ bonds in $\mathrm{TeO}_{3}$ units. The $\mathrm{Sr}-\mathrm{O}$ bond length is reported to be $\sim 2.65 \AA$ (Wunderlich, 2007), but due to weak X-ray scattering weight factors of $\mathrm{Sr}-\mathrm{O}$ their contribution is small in $G(r)$. The broad band in the range of 3.1-5.0 $\AA$ shows maxima at 3.61 $\AA$ and $4.10 \AA$ which are due to the Te-Te correlations (Thomas, 1988; Shimizugawa et al., 1995). As the concentration of $\mathrm{SrO}$ increases from 5 to 10 mol.\%, the Te-Te maxima peak shifts slightly from $3.61 \AA$ to $3.65 \AA$.

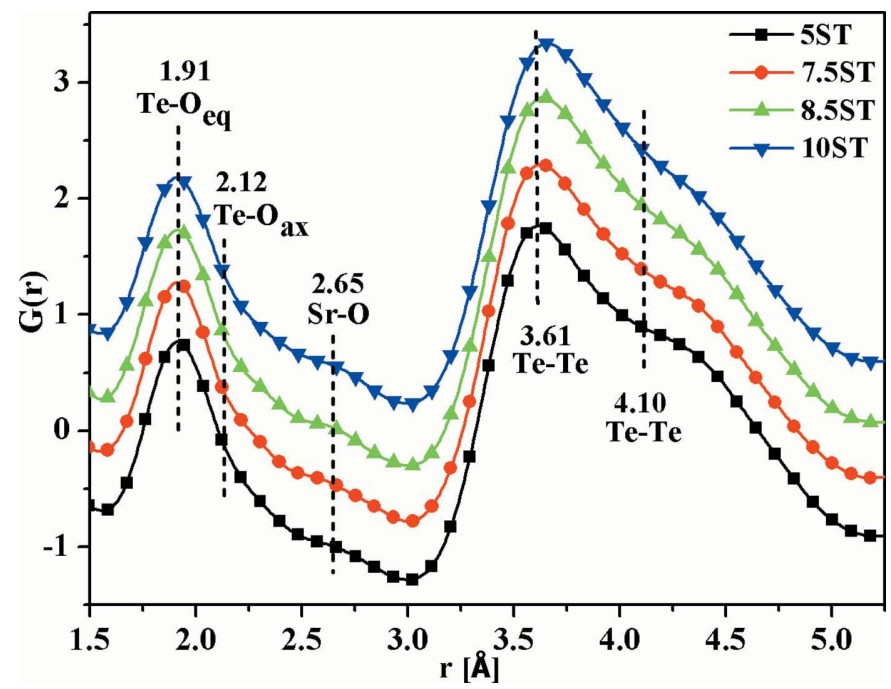

Figure 10

$G(r)$ of all the glass samples (successive curves are shifted by 0.5 units along the $y$ axis for clarity). 
The $G(r)$ gives the weighted sum of correlations of all the atomic pairs in the sample. It is difficult to obtain structural parameters such as bond lengths and the coordination numbers from $G(r)$ due to the strong overlapping of the different atomic pair correlations. Therefore, it is important to find the partial atomic pair distribution functions, $g_{i j}(r)$, to determine the structural parameters accurately. The RMC simulations provided the necessary $g_{i j}(r)$ distributions by simulating the structure factor, $S(Q)$, of the samples.

3.4.3. Short-range structure of strontium tellurite glasses by RMC modelling. The RMC simulations of the glass samples determined their native atomic structure including $\mathrm{Te}-\mathrm{O}$ speciation, partial atomic pair correlations, bond lengths and the bond angle $(\mathrm{O}-\mathrm{Te}-\mathrm{O}, \mathrm{O}-\mathrm{Sr}-\mathrm{O})$ distributions of the local network with accuracy. Due to the low concentration and hence smaller weight factors of $\mathrm{Sr}-\mathrm{O}$ atomic pairs (Table 3), the coordination number, bond length and bond angle $(\mathrm{O}-$

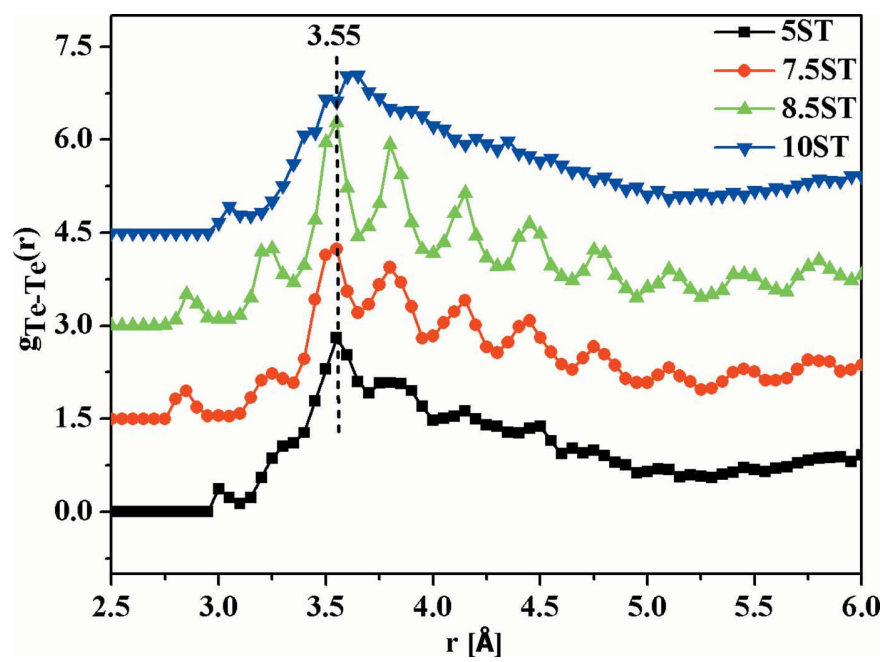

Figure 11

Partial atomic pair correlations for Te-Te $\left(g_{\mathrm{Te}-\mathrm{Te}}\right)$ in glass samples (curves are shifted successively along the $y$ axis by 1.5 units for clarity).

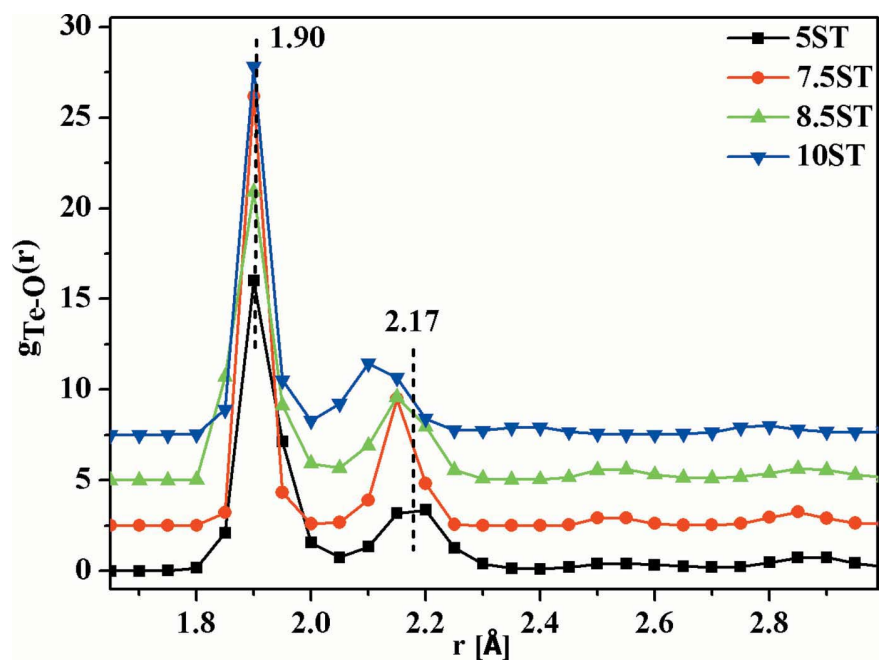

Figure 12

Partial atomic pair correlations for $\mathrm{Te}-\mathrm{O}\left(g_{\mathrm{Te}-\mathrm{O}}\right)$ in glass samples (curves are shifted successively along the $y$ axis by 2.5 units for clarity).
$\mathrm{Sr}-\mathrm{O}$ ) could not be calculated accurately from the calculated data generated by the RMC model and hence are not presented herein.

The experimental and calculated structure factors, $[S(Q)-1]$, show a good fit and are represented in Fig. 9. The partial pair distribution functions for $\mathrm{Te}-\mathrm{Te}$ and $\mathrm{Te}-\mathrm{O}$, i.e. $g_{\mathrm{Te}-\mathrm{Te}}(r)$ and $g_{\mathrm{Te}-\mathrm{O}}(r)$, are shown in Figs. 11 and 12 respectively. The first strong peak (Fig. 11) in the Te-Te correlation functions is at $3.55 \AA$, $3.54 \AA$, $3.55 \AA$ and $3.63 \AA$ for 5ST, 7.5ST, 8.5ST and 10ST glass samples, respectively (Table 5). The first peak position of the Te-O correlation function (Fig. 12) is at 1.90 (1) $\AA$ in all the glass samples (Table 5). The Te-O bond lengths show the distribution of peaks in the tellurite glasses: the axial $\mathrm{Te}-\mathrm{O}_{\mathrm{ax}}$ bonds are longer, in the range of 2.10 to $2.17 \AA$, whereas the equatorial $\mathrm{Te}-\mathrm{O}_{\mathrm{eq}}$ bonds are shorter $(1.90 \AA)$. These results are in excellent agreement with the reported structural data on tellurite glasses (Barney et al.,

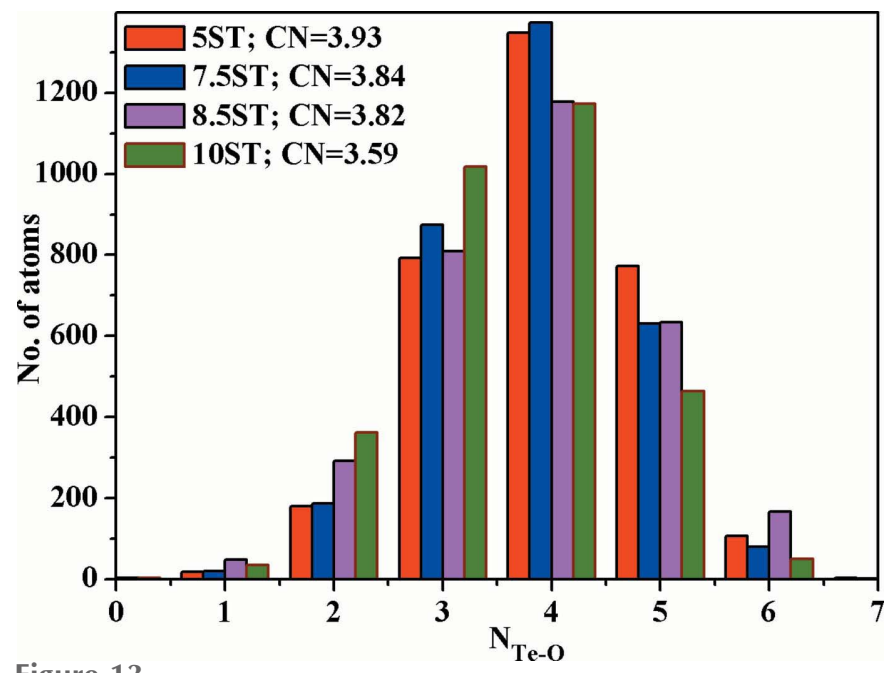

Figure 13

$\mathrm{Te}-\mathrm{O}$ coordination distributions in the glass samples.

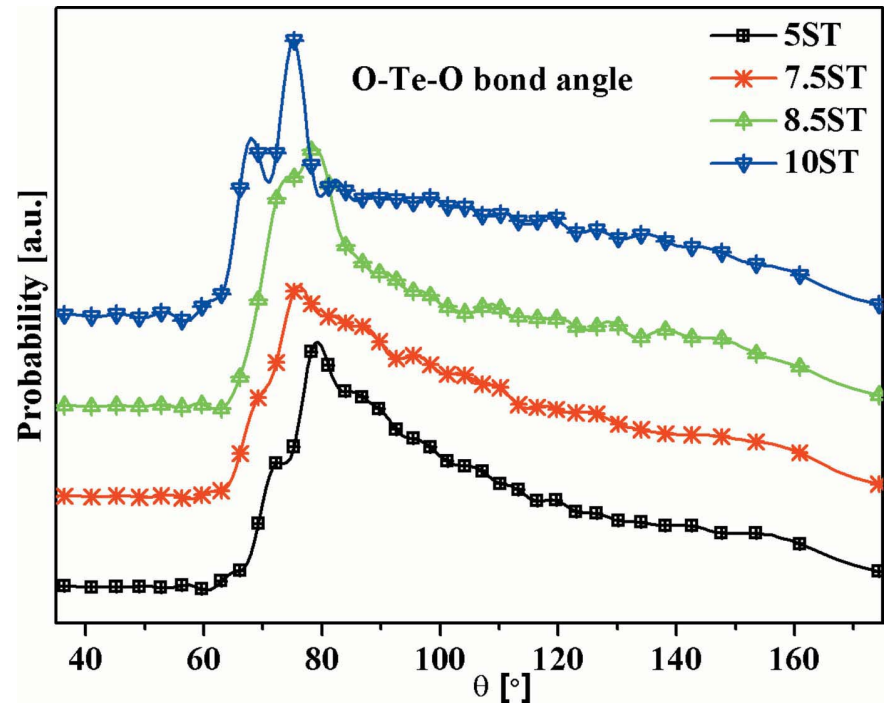

Figure 14

Bond angle distributions for $\mathrm{O}-\mathrm{Te}-\mathrm{O}$ linkages in strontium tellurite glasses (successive curves are shifted by 0.5 units for clarity). 
2013; Hoppe et al., 2004; Kaur et al., 2019). The mean Te-O coordination numbers for 5ST, 7.5ST, 8.5ST and 10ST glasses are $3.93(1), 3.84(1), 3.82$ (2) and 3.59 (1), respectively. The distribution of different structural species and the mean $N_{\mathrm{Te}-\mathrm{O}}$ is shown in Fig. 13.

The Te-O speciation revealed that the glass network predominantly contains $\mathrm{TeO}_{4}$ with small amounts of $\mathrm{TeO}_{3}$ units. However, $\mathrm{TeO}_{4}$ transforms into $\mathrm{TeO}_{3}$ units with an increase in the concentration of the modifier, i.e. SrO. The $\mathrm{O}-$ $\mathrm{Te}-\mathrm{O}$ bond angle distribution (Fig. 14) is found to be peaked at $79(1)^{\circ}, 75(1)^{\circ}, 77(1)^{\circ}$ and $75(1)^{\circ}$ in 5ST, 7.5ST, 8.5ST and 10ST glasses, respectively (Table 5). Generally, the bond angle distributions $(\mathrm{O}-\mathrm{Te}-\mathrm{O})$ of the glassy $\mathrm{TeO}_{2}$ show two distinct peaks in the angular range of $70-105^{\circ}$ and $150-170^{\circ}$. The peak in the lower angle range $\left(70-105^{\circ}\right)$ is due to the $\mathrm{O}_{\mathrm{eq}}-\mathrm{Te}-\mathrm{O}_{\mathrm{eq}}$ (equatorial linkages) and $\mathrm{O}_{\mathrm{eq}}-\mathrm{Te}-\mathrm{O}_{\mathrm{ax}}$ (equatorial and axial) bonds while the peak in the higher angle range $\left(150-170^{\circ}\right)$ is due to the $\mathrm{O}_{\mathrm{ax}}-\mathrm{Te}-\mathrm{O}_{\mathrm{ax}}$ linkages (Khanna et al., 2018). In the present case, the maxima in the $\mathrm{O}-\mathrm{Te}-\mathrm{O}$ distribution occur at $\sim 79^{\circ}$ and therefore the strontium tellurite glass network contains mostly $\mathrm{O}_{\text {eq }}-\mathrm{Te}-\mathrm{O}_{\text {eq }}$ and/or $\mathrm{O}_{\text {eq }}-\mathrm{Te}-\mathrm{O}_{\mathrm{ax}}$ bonds in the $\mathrm{TeO}_{4}$ and $\mathrm{TeO}_{3}$ structural units with bridging, non-bridging and terminal oxygens. In the higher angle range of $150-170^{\circ}$, there are no peaks (Fig. 14) which indicates that the concentration of $\mathrm{O}_{\mathrm{ax}}-\mathrm{Te}-\mathrm{O}_{\mathrm{ax}}$ linkages is small in the glass structure (Pietrucci et al., 2008). However, the bond angle and bond lengths show no significant variation with changes in concentration of SrO (Table 5).

\subsection{Structure of strontium tellurite anti-glass samples}

The HEXRD data for anti-glass (xST_CR1; $x=7.5$ and 8.5 mol. \%) samples are shown in Fig. 15. For peak indexing, the HEXRD data are converted into $d$ spacing (interplanar spacing) using $Q=2 \pi / d$. The sharp XRD peaks of anti-glass samples match well with the cubic $\mathrm{SrTe}_{5} \mathrm{O}_{11}$ phase [Joint

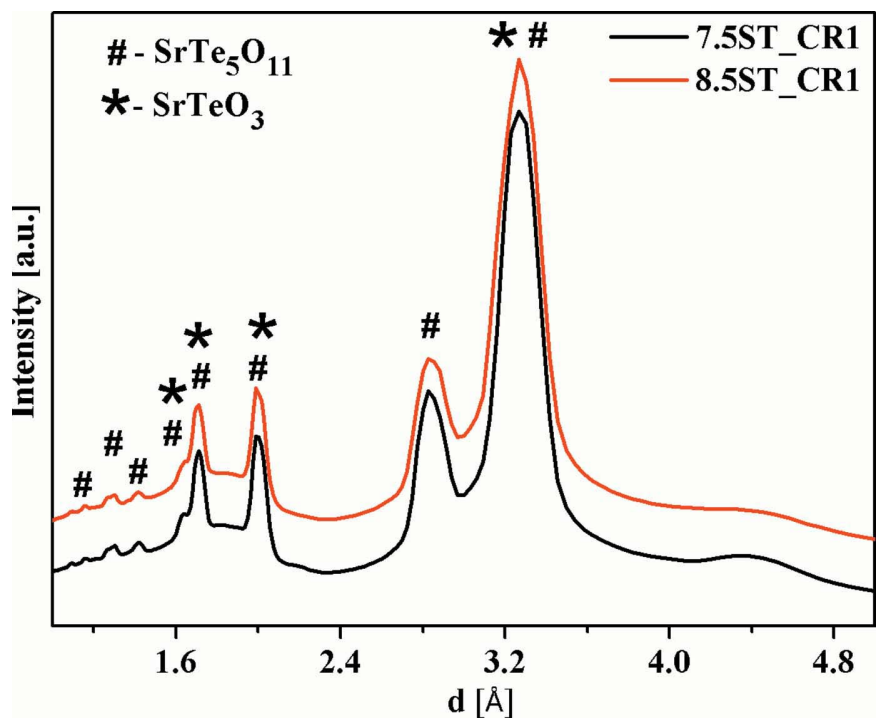

Figure 15

$\mathrm{X}$-ray scattering raw data in the strontium tellurite glass samples (successive curves are shifted by 0.1 units for clarity).
Committee on Powder Diffraction Standards (JCPDS) file No. 36-1235] but an additional monoclinic $\mathrm{SrTeO}_{3}$ phase (JCPDS file No. 34-1280) had to be incorporated during Rietveld refinement for better profile matching.

The $\mathrm{SrTe}_{5} \mathrm{O}_{11}$ is an anti-glass phase as reported earlier (Kaur, Khanna et al., 2018) and has a face-centred cubic unit cell, while the $\mathrm{SrTeO}_{3}$ has monoclinic symmetry. The broad Raman bands (Fig. 6) and the sharp XRD peaks (Fig. 15) confirm the anti-glass nature of xST_CR1 $(x=7.5,8.5 \mathrm{~mol} . \%)$ samples. The short-range and long-range order structural analyses of anti-glass samples were carried out by PDF analysis and Rietveld refinement (discussed below). The structure factors, $S(Q)$, of anti-glass (xST_CR1; $x=7.5$, 8.5 mol.\%) samples were calculated by PDFget $X 2$ software up to $Q_{\max }=18.5 \AA^{-1}$ and are shown in Fig. 16 .

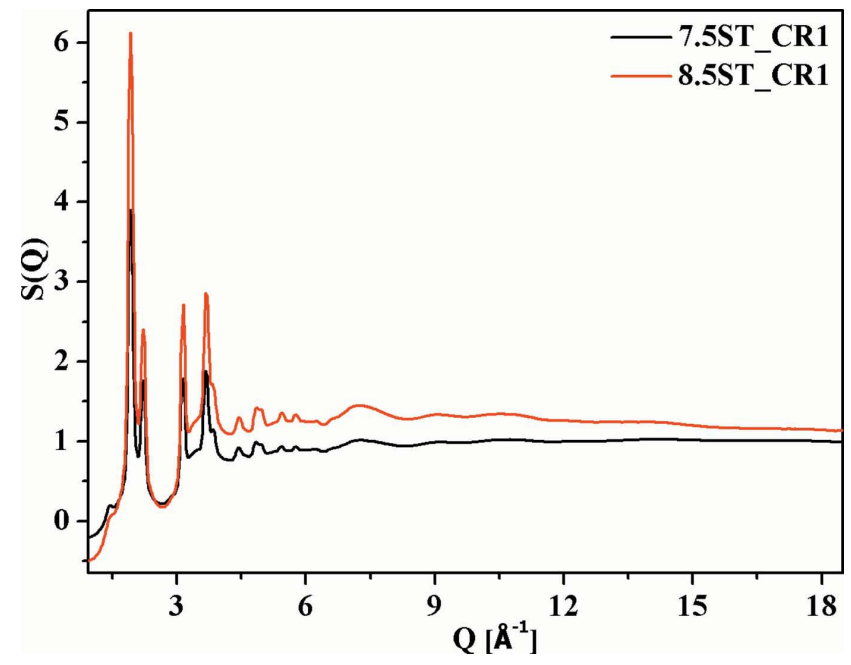

Figure 16

The structure factor $S(Q)$ for the anti-glass samples (successive curves are shifted by 0.15 units along the $y$ axis for clarity).

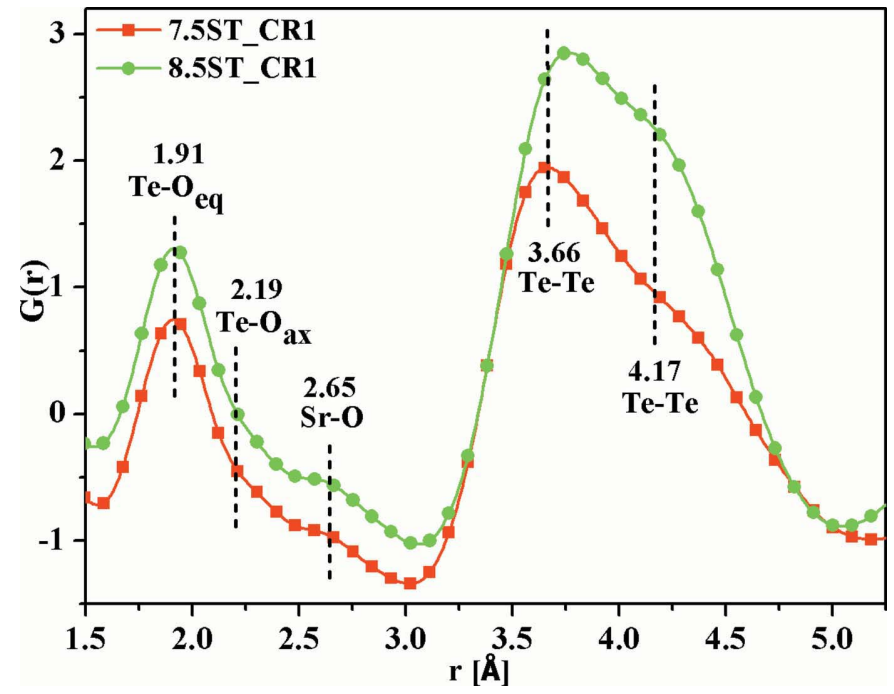

Figure 17

$G(r)$ of the anti-glass samples (successive curves are shifted by 0.5 units along the $y$ axis for clarity). 
Table 7

Unit-cell parameters and the Rietveld refinement parameters for the antiglass (7.5ST_CR1) sample.
$5.646(1)$

$28.303(7)$

$5.932(1)$

$28.625(1)$

$114.336(7)$

$0.350(1)$

$0.645(7)$

$0.505(7)$

$1.65(2)$

3.5.1. $G(r)$ of strontium tellurite anti-glass samples. The reduced pair correlation function, $G(r)$ (Fig. 17), for the two anti-glass samples is obtained from the Fourier transformation of $S(Q)$ using the Lorch modification function. The $G(r)$ for the anti-glass samples is very similar to that of glasses. This is due to the fact that the anti-glass and glass samples possess similar atomic arrangements and bond lengths of the atomic pairs. In the anti-glass samples, the peak at $1.91 \AA$ (Fig. 17) is due to the $\mathrm{Te}-\mathrm{O}_{\mathrm{eq}}$ bonds of the $\mathrm{TeO}_{4}$ tbp units.

The weak peak at $2.65 \AA$ is due to $\mathrm{Sr}-\mathrm{O}$ bonds similar to those of the glass samples. Additionally, the anti-glass samples show a broad peak in the range of 3.1-5.0 $⿱$ with maxima at $3.66 \AA$ and $4.17 \AA$ due to the Te-Te interatomic linkages. On increasing the concentration of SrO from 7.5 to $8.5 \mathrm{~mol}$ \%, the Te-Te separation increases from 3.66 to $3.76 \AA$.

3.5.2. Structure of anti-glass samples by Rietveld analysis. The HEXRD data of one anti-glass sample (7.5ST_CR1) were analysed by the Fullprof Rietveld technique and the sample shows the formation of anti-glass $\mathrm{SrTe}_{5} \mathrm{O}_{11}$ and anti-glass $\mathrm{SrTeO}_{3}$ phases (Fig. 15). The $\mathrm{SrTe}_{5} \mathrm{O}_{11}$ has a face-centred cubic unit cell and $F m 3 m$ space group (JCPDS powder diffraction file No. 36-1235), while the $\mathrm{SrTeO}_{3}$ has monoclinic symmetry

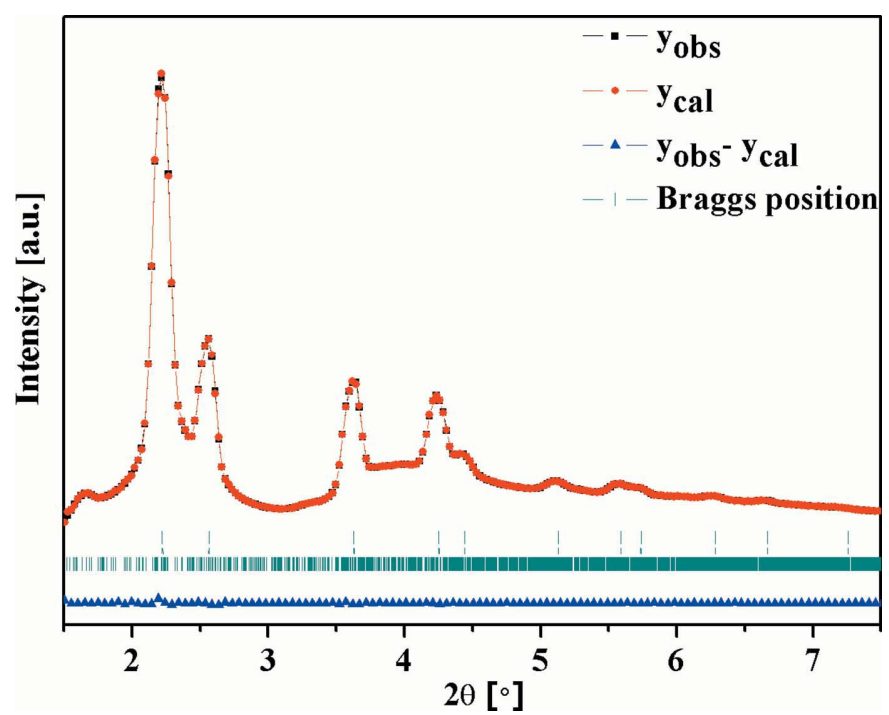

Figure 18

Rietveld refinement of HEXRD data of the anti-glass (7.5ST_CR1) sample.

with the $C 2 / c$ space group (JCPDS powder diffraction file No. 34-1280). The initial unit-cell parameters for the Rietveld profile matching were taken from their respective JCPDS files. The starting structural parameters for the cubic $\mathrm{SrTe}_{5} \mathrm{O}_{11}$ phase were taken as $a=b=c=5.655 \AA$, while for the $\mathrm{SrTeO}_{3}$ phase, the initial lattice parameters were taken as $a=28.240$, $b=5.926$ and $c=28.440 \AA$, and $\alpha=\gamma=90^{\circ}$ with $\beta=114.330^{\circ}$.

The Rietveld analysis is a structure refinement technique for crystalline materials. Here, for the 7.5ST_CR1 anti-glass sample, the profile matching using the constant scale factor was carried out by the Fullprof program. The complete structure refinement was not possible because the samples do not possess long-range order of the anions. For the comprehensive profile analysis, all the lattice parameters, profile shape parameters, thermal displacement factor and the

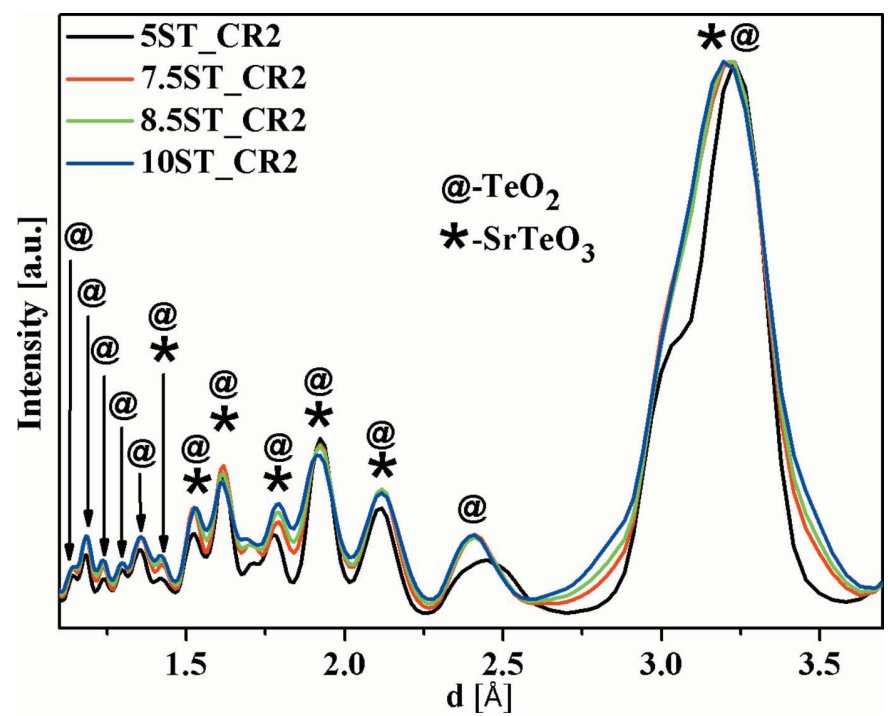

Figure 19

X-ray raw data for the crystalline strontium tellurite (xST_CR2; $x=5,7.5$, 8.5 and $10 \mathrm{~mol} . \%)$ samples.

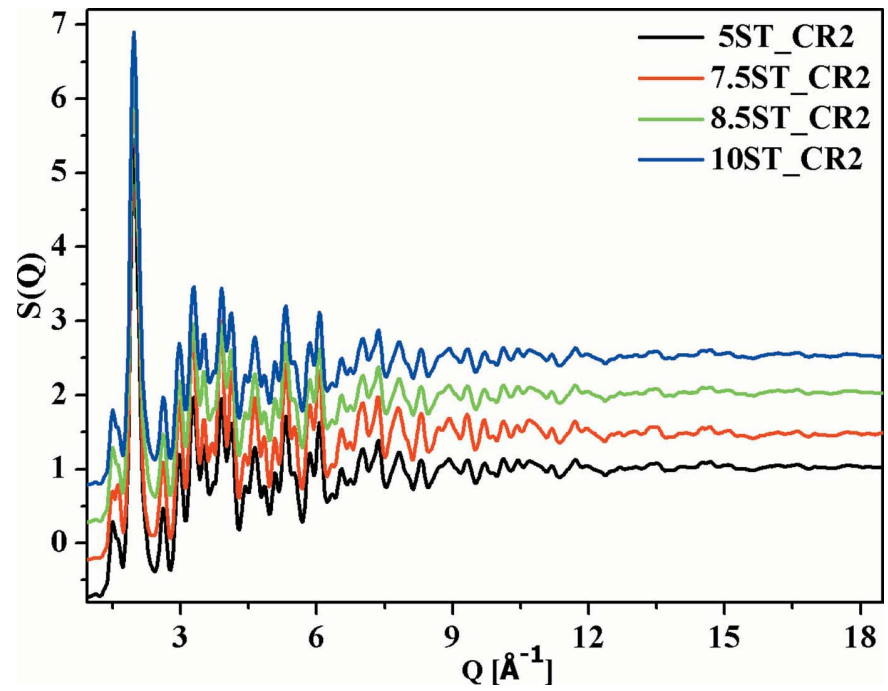

Figure 20

The structure factors $S(Q)$ for the crystalline (xST_CR2; $x=5,7.5,8.5$ and $10 \mathrm{~mol} . \%$ ) samples (successive curves are displaced by 0.50 units for clarity). 
background parameters were refined and the value of $\chi^{2}$ is reduced to 1.65 (2) (Table 7 ). The data were refined three times to calculate the uncertainty in the refined parameters and to check the reproducibility of the results.

The final refined data are shown in Fig. 18. The structural parameters from the Rietveld technique are: $a=b=c=$ 5.646 (1) $\AA$ for the anti-glass $\mathrm{SrTe}_{5} \mathrm{O}_{11}$ phase, and $a=$ 28.303 (7), $b=5.932$ (1), $c=28.625$ (1) $\AA, \alpha=\gamma=90^{\circ}$ and $\beta=$ $114.336(7)^{\circ}$ for the anti-glass $\mathrm{SrTeO}_{3}$ phase (Table 7).

\subsection{Structure of strontium tellurite crystalline samples}

The HEXRD patterns for the crystalline samples (xST_CR2; $x=5,7.5,8.5$ and 10 mol.\%) show several sharp peaks and are shown in Fig. 19. The crystalline samples show the presence of two phases, the first is the orthorhombic $\mathrm{TeO}_{2}$

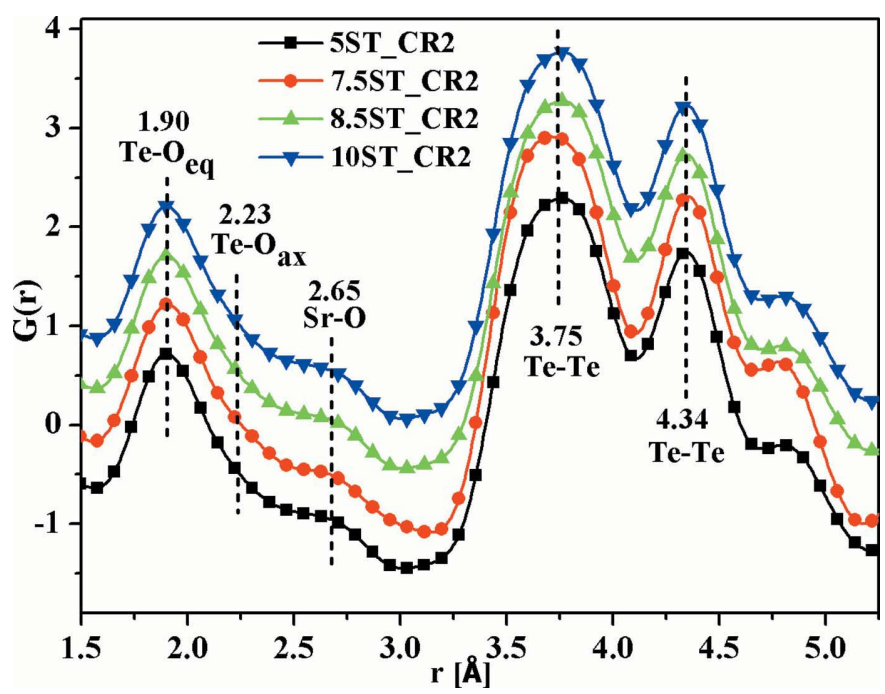

Figure 21

$G(r)$ of the crystalline (xST_CR2; $x=5,7.5,8.5$ and 10 mol.\%) samples (successive curves are shifted by 0.5 units for clarity).

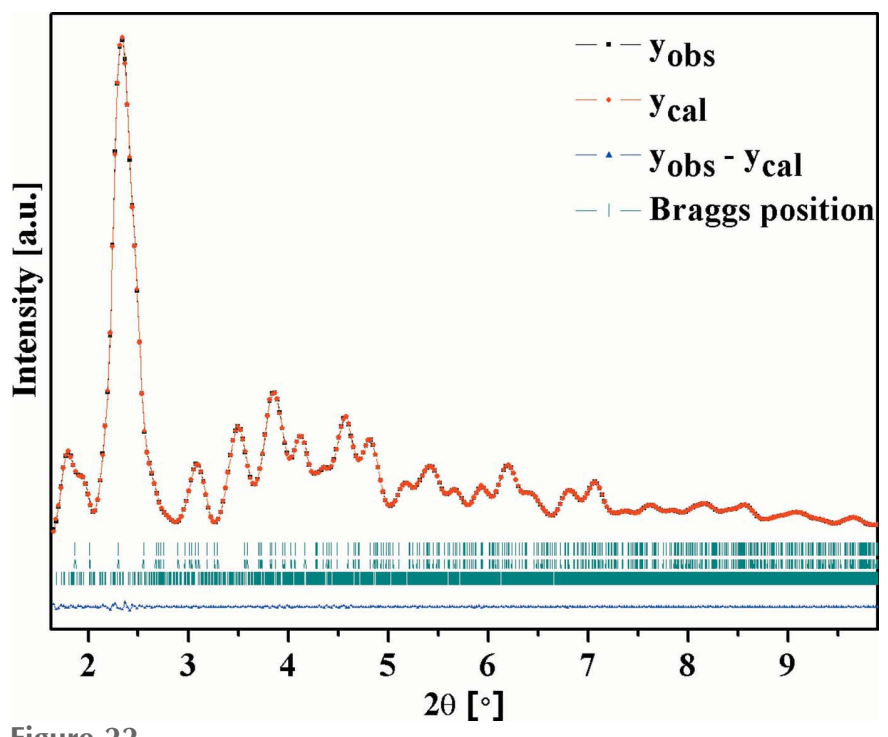

Figure 22

Rietveld refinement of HEXRD data for the crystalline (10ST_CR2) sample.
Table 8

The unit-cell parameters and Rietveld refinement parameters for the crystalline 10ST_CR2 sample.

\begin{tabular}{ll}
\hline $\mathrm{TeO}_{2}$ (orthorhombic) & \\
$a(\AA)$ & $5.314(5)$ \\
$b(\AA)$ & $11.344(8)$ \\
$c(\AA)$ & $5.429(18)$ \\
$\mathrm{SrTeO}_{3}$ (monoclinic) & \\
$a(\AA)$ & $27.205(15)$ \\
$b(\AA)$ & $5.777(6)$ \\
$c(\AA)$ & $27.533(12)$ \\
$\beta\left({ }^{\circ}\right)$ & $114.49(5)$ \\
& \\
$R_{\mathrm{p}}$ & $0.40(5)$ \\
$R_{\mathrm{wp}}$ & $0.64(4)$ \\
$R_{\exp }$ & $0.56(9)$ \\
$\chi^{2}$ & $1.37(4)$ \\
\hline
\end{tabular}

(labelled as @) and the second is the monoclinic $\mathrm{SrTeO}_{3}$ phase (labelled as *).

The structure factor, $S(Q)$, of the four crystalline samples was calculated by PDFget $X 2$ software up to $Q_{\max }=18.5 \AA^{-1}$ and is shown in Fig. 20.

3.6.1. $G(r)$ of the strontium tellurite crystalline samples. The reduced pair correlation functions, $G(r)$ (Fig. 21), for all the crystalline samples were obtained with PDFget $X 2$ software. The atomic pair correlation distribution of the crystalline phase has peaks at $1.90 \AA$ and $2.65 \AA$ which represent the $\mathrm{Te}-\mathrm{O}_{\mathrm{eq}}$ and $\mathrm{Sr}-\mathrm{O}$ bond lengths, similar to those of the glass and anti-glass samples. However, the two peaks at $3.75 \AA$ and $4.34 \AA$ are more prominent and better resolved and are due to the $\mathrm{Te}-\mathrm{Te}$ correlations. It is found that, with annealing and crystallization, the Te-Te distances shift towards higher $r$ values as compared with the glass and anti-glass samples (Fig. 21).

3.6.2. Structure of the crystalline sample by Rietveld analysis. The HEXRD data of all the crystalline samples match well with the monoclinic $\mathrm{SrTeO}_{3}$ and the orthorhombic $\mathrm{TeO}_{2}$ phases (Fig. 19). The HEXRD data of one crystalline sample, i.e. 10ST_CR2, were modelled by Rietveld analysis to determine the unit-cell parameters.

In the case of this crystalline sample, the profile matching using the constant scale factor was carried out by the Fullprof program with the pseudo-Voigt function to model the peak profile shape. The different profile shape parameters, lattice parameters, thermal displacement factor and the background parameters were refined during the fitting to minimize the $\chi^{2}$ value. The initial parameters were taken from the crystallographic information file (CIF) available at the crystallography open database (COD). The CIF files (COD Nos 1528441 and 1011183) were used for the monoclinic $\mathrm{SrTeO}_{3}$ phase and for orthorhombic $\mathrm{TeO}_{2}$, respectively.

The starting structural parameters for the $\mathrm{SrTeO}_{3}$ (space group $C 2 / c$ ) for Rietveld refinement were taken as $a=28.340$, $b=5.940$ and $c=28.658 \AA$ and $\alpha=\gamma=90^{\circ}$ with $\beta=114.263^{\circ}$, and for the orthorhombic $\mathrm{TeO}_{2}$ phase (space group Pcab), the initial lattice parameters were $a=5.500, b=11.750$ and $c=$ $5.590 \AA$ and $\alpha=\beta=\gamma=90^{\circ}$. The refined data are shown in Fig. 22 and the refined structural parameters (Table 8) calcu- 
lated from the Rietveld program are $a=27.205$ (15), $b=$ 5.777 (6) and $c=27.533$ (12) $\AA$ with $\beta=114.49(5)^{\circ}$ for the monoclinic $\mathrm{SrTeO}_{3}$ phase, and $a=5.314$ (5), $b=11.344$ (8) and $c=5.429$ (18) $\AA$, and $\alpha=\beta=\gamma=90^{\circ}$ or the orthorhombic $\mathrm{TeO}_{2}$ phase. The error in the refined parameters is calculated by repeating the refinement process three times and is given in Table 8.

\section{Conclusions}

The HEXRD data of strontium tellurite glass, anti-glass and crystalline samples were analysed to determine the shortrange structural properties, i.e. the coordination environments of Te with oxygens $\left(N_{\mathrm{Te}-\mathrm{O}}\right)$, nearest-neighbour distances, distribution of $\mathrm{Te}-\mathrm{O}$ and $\mathrm{Te}-\mathrm{Te}$ distances and bond angle distributions. RMC simulations revealed that the Te-O coordination number is in the range 3.93-3.59 in glasses. HEXRD studies confirm the formation of anti-glass $\mathrm{SrTe}_{5} \mathrm{O}_{11}$ and $\mathrm{SrTeO}_{3}$ phases on heat treatment of glasses at $350^{\circ} \mathrm{C}$ for $1 \mathrm{~h}$. On heating the samples further at $450^{\circ} \mathrm{C}$, the crystalline phases of monoclinic $\mathrm{SrTeO}_{3}$ and orthorhombic $\mathrm{TeO}_{2}$ are produced. The results from Raman spectroscopy and RMC simulations on $\mathrm{Te}-\mathrm{O}$ speciation are consistent and confirm the structural transformation $\mathrm{TeO}_{4} \rightarrow \mathrm{TeO}_{3}$ with an increase in $\mathrm{SrO}$ concentration in the $x \mathrm{SrO}-(100-x) \mathrm{TeO}_{2}$ system. The devitrification of $x \mathrm{SrO}-(100-x) \mathrm{TeO}_{2}$ glasses with heat treatment takes place via the formation of anti-glass as a partially disordered intermediate phase between the glass and crystalline phases.

\section{Acknowledgements}

Portions of this research were carried at the light source PETRA III of DESY, a member of the Helmholtz Association (HGF).

\section{Funding information}

Funding for this research was provided by: Inter University Accelerator Centre, New Delhi, UGC-DAE Consortium for Scientific Research, University Grants Commission, Mumbai. Financial support by the Department of Science and Technology (Government of India) provided within the framework of the India @DESY collaboration is gratefully acknowledged.

\section{References}

Affatigato, M. (2015). Modern Glass Characterization. Hoboken: John Wiley \& Sons.

Barney, E. R., Hannon, A. C., Holland, D., Umesaki, N., Tatsumisago, M., Orman, R. G. \& Feller, S. (2013). J. Phys. Chem. Lett. 4, 2312 2316.

Bertrand, A., Carreaud, J., Delaizir, G., Shimoda, M., Duclère, J., Colas, M., Belleil, M., Cornette, J., Hayakawa, T., Genevois, C., Veron, E., Allix, M., Chenu, S., Brisset, F. \& Thomas, P. (2015). Cryst. Growth Des. 15, 5086-5096.

Blasse, G., Dirksen, G., Oomen, E. \& Trömel, M. (1986). J. Solid State Chem. 63, 148-153.
Burckhardt, H.-G. \& Trömel, M. (1983). Acta Cryst. C39, 13221323.

Cormier, L. (2018). Diffraction and X-ray Absorption Spectroscopy, edited by Akira Takada, John Parker, Alicia Duran \& Klaus Bange. Teaching Glass Better: 10th Anniversary of the ICG Summer School. ICG, International Commission of Glass 033, ch. 4, pp. $57-$ 81.

Egami, T. \& Billinge, S. J. (2003). Underneath the Bragg Peaks: Structural Analysis of Complex Materials. Netherlands: Pergamon, Elsevier Imprint.

Elliott, S. R. (1991). Nature, 354, 445-452.

El-Mallawany, R. A. (2011). Tellurite Glasses Handbook: Physical Properties and Data. USA: CRC Press.

Evrard, G. \& Pusztai, L. (2005). J. Phys. Condens. Matter, 17, S1-S13. Fábián, M. \& Araczki, C. (2016). Phys. Scr. 91, 054004.

Fabian, M., Svab, E. \& Krezhov, K. (2016). J. Non-Cryst. Solids, 433, 6-13.

Gulenko, A., Masson, O., Berghout, A., Hamani, D. \& Thomas, P. (2014). Phys. Chem. Chem. Phys. 16, 14150-14160.

Gupta, N., Hirdesh, Kaur, R., Khanna, A., Singh, S. \& Gupta, B. K. (2019). J. Non-Cryst. Solids, 513, 24-35.

Gupta, N. \& Khanna, A. (2018). J. Non-Cryst. Solids, 481, 594603.

Hoppe, U., Yousef, E., Rüssel, C., Neuefeind, J. \& Hannon, A. (2004). J. Phys. Condens. Matter, 16, 1645-1663.

Johnson, R., Price, D., Susman, S., Arai, M., Morrison, T. \& Shenoy, G. (1986). J. Non-Cryst. Solids, 83, 251-271.

Kaur, A., Hirdesh, Khanna, A., Fábián, M., Krishna, P. S. R. \& Shinde, A. B. (2019). Mater. Res. Bull. 110, 239-246.

Kaur, R., Kaur, R., Khanna, A. \& González, F. (2018). AIP Conf. Proc. 1942, 070028.

Kaur, R., Khanna, A., González-Barriuso, M., González, F. \& Chen, B. (2018). Mater. Res. Bull. 106, 288-295.

Khanna, A., Fábián, M., Hirdesh, Krishna, P. S. R., Benmore, C. J., Kaur, A., Kaur, A., Shinde, A. B., Rajput, P. \& Jha, S. N. (2018). J. Non-Cryst. Solids, 495, 27-34.

Li, Y., Fan, W., Sun, H., Cheng, X., Li, P. \& Zhao, X. (2010). J. Appl. Phys. 107, 093506-093506.

Manning, S. (2011). PhD thesis, The University of Adelaide, Australia.

McLaughlin, J., Tagg, S., Zwanziger, J., Haeffner, D. \& Shastri, S. (2000). J. Non-Cryst. Solids, 274, 1-8.

McLaughlin, J. \& Zwanziger, J. (1999). J. Mol. Graph. Model. 17, $275-$ 284.

McLaughlin, J. C., Tagg, S. \& Zwanziger, J. (2001). J. Phys. Chem. B, 105, 67-75.

Moharram, A. (2015). Glass Phys. Chem. 41, 453-459.

Moss, S. \& Price, D. (1985). Physics of Disordered Materials, pp. 7795. Berlin: Springer.

Petkov, V. (2008). Mater. Today, 11, 28-38.

Pietrucci, F., Caravati, S. \& Bernasconi, M. (2008). Phys. Rev. B, 78, 064203.

Qiu, X., Thompson, J. W. \& Billinge, S. J. L. (2004). J. Appl. Cryst. 37, 678.

Rivera, V. \& Manzani, D. (2017). Technological Advances in Tellurite Glasses. Berlin: Springer.

Salmon, P. S. (1994). Proc. R. Soc. London Ser. A, 445, 351-365.

Schell, N., King, A., Beckmann, F., Fischer, T., Müller, M. \& Schreyer, A. (2014). Mater. Sci. Forum, 772, 57-61.

Shimizugawa, Y., Maeseto, T., Suehara, S., Inoue, S. \& Nukui, A. (1995). J. Mater. Res. 10, 405-410.

Soper, A. K. \& Barney, E. R. (2012). J. Appl. Cryst. 45, 1314-1317.

Thomas, P. (1988). J. Phys. C Solid State Phys. 21, 4611-4627.

Toby, B. H. (2006). Powder Diffr. 21, 67-70.

Trömel, M., Hützler, W. \& Münch, E. (1985). J. Less-Common Met. 110, 421-424.

Trömel, M., Münch, E., Blasse, G. \& Dirksen, G. (1988). J. Solid State Chem. 76, 345-354. 
Wang, J., Vogel, E. \& Snitzer, E. (1994). Opt. Mater. 3, 187-203.

Whittles, Z., Marple, M., Hung, I., Gan, Z. \& Sen, S. (2018). J. NonCryst. Solids, 481, 282-288.

Wilding, M. C., Delaizir, G., Benmore, C. J., Gueguen, Y., Dolhen, M., Duclère, J.-R., Chenu, S., Sukenaga, S. \& McMillan, P. F. (2016). J. Non-Cryst. Solids, 451, 68-76.
Wunderlich, W. (2007). arXiv:0711.0567.

Young, R. A. (1993). The Rietveld Method. International Union of Crystallography Monographs on Crystallography. IUCr/Oxford University Press.

Zhou, D., Wang, R., Yang, Z., Song, Z., Yin, Z. \& Qiu, J. (2011). J. Non-Cryst. Solids, 357, 2409-2412. 